University of Wollongong

Research Online

Faculty of Engineering and Information

Faculty of Engineering and Information

Sciences - Papers: Part A

Sciences

$1-1-2015$

Behavior of concrete-filled FRP tubes under cyclic axial compression

B Zhang

Hong Kong Polytechnic University

$\mathrm{T} \mathrm{Yu}$

University of Wollongong, taoy@uow.edu.au

J G. Teng

Hong Kong Polytechnic University, cejgteng@polyu.edu.hk

Follow this and additional works at: https://ro.uow.edu.au/eispapers

Part of the Engineering Commons, and the Science and Technology Studies Commons

Research Online is the open access institutional repository for the University of Wollongong. For further information contact the UOW Library: research-pubs@uow.edu.au 


\title{
Behavior of concrete-filled FRP tubes under cyclic axial compression
}

\author{
Abstract \\ Concrete-filled fiber-reinforced polymer (FRP) tubes (CFFTs) are an attractive form of hybrid compression \\ members incorporating FRP. CFFTs have several advantages over traditional column forms, including their \\ excellent corrosion resistance and ductility. Much research has been conducted on CFFTs over recent \\ years, but no systematic experimental study has been concerned with the cyclic axial compressive \\ behavior of CFFTs with a filament-wound FRP tube; such studies are needed for the development of a \\ cyclic stress-strain model for the concrete in CFFTs. This paper therefore presents an experimental study \\ on the behavior of circular CFFTs under cyclic axial compression. The experimental program included the \\ strength of concrete as a key variable so that it also provides a much needed supplement to the very \\ limited existing research on the cyclic compressive behavior of FRP-confined high-strength concrete \\ (HSC). The test results are compared with a monotonic stress-strain model and a cyclic stress-strain \\ model for FRP-confined concrete, both of which have been based on test databases that are limited to \\ concrete confined with an FRP wrap and include only a small number of tests for HSC. The test results \\ show that the cyclic axial stress-strain behavior of concrete in CFFTs is generally similar to that of \\ concrete confined by an FRP wrap. The test results also show that the monotonic stress-strain model \\ perform reasonably well for HSC in CFFTs, but revisions to the cyclic stress-strain model are needed \\ before it can provide accurate predictions for HSC in cyclically loaded CFFTs.

\section{Disciplines} \\ Engineering | Science and Technology Studies \\ Publication Details \\ Zhang, B., Yu, T. \& Teng, J. G. (2015). Behavior of concrete-Filled FRP tubes under cyclic axial \\ compression. Journal of Composites for Construction, 19 (3), 04014060-1-04014060-13.
}




\title{
Behavior of Concrete-Filled FRP Tubes under Cyclic-Axial Compression
}

\author{
B. Zhang ${ }^{1}$, T. $\mathrm{Yu}^{2}$, and J. G. Teng ${ }^{3}$ \\ ${ }^{1} \mathrm{PhD}$ Candidate, Department of Civil and Environmental Engineering, The Hong Kong Polytechnic University, \\ Hong Kong, China. \\ ${ }^{2}$ Senior Lecturer, School of Civil, Mining and Environmental Engineering, Faculty of Engineering and \\ Information Sciences, University of Wollongong, Northfields Avenue, Wollongong, NSW 2522, Australia \\ (Corresponding author). Email: taoy@uow.edu.au \\ ${ }^{3}$ Chair Professor of Structural Engineering, Department of Civil and Environmental Engineering, The Hong Kong \\ Polytechnic University, Hong Kong, China.
}

\section{ABSTRACT}

Concrete-filled FRP tubes (CFFTs) are an attractive form of hybrid compression members incorporating FRP. CFFTs have several advantages over traditional column forms, including their excellent corrosion resistance and ductility. Much research has been conducted on CFFTs over recent years, but no systematic experimental study has been concerned with the cyclic axial compressive behavior of CFFTs with a filament-wound FRP tube; such studies are needed for the development of a cyclic stress-strain model for the concrete in CFFTs. This paper therefore presents an experimental study on the behavior of circular CFFTs under cyclic axial compression. The experimental program included the strength of concrete as a key variable so that it also provides a much needed supplement to the very limited existing research on the cyclic compressive behavior of FRP-confined high strength concrete (HSC). The test results are compared with a monotonic stress-strain model and a cyclic stress-strain model for FRP-confined concrete, both of which have been based on test databases which are limited to concrete confined with an FRP wrap and include only a small number of tests for HSC. The test results show that the cyclic axial stress-strain behavior of concrete in CFFTs is generally similar to that of concrete confined by an FRP wrap. The test results also show that the monotonic stress-strain model perform reasonably well for HSC in CFFTs, but revisions 
to the cyclic stress-strain model are needed before it can provide accurate predictions for HSC in cyclically loaded CFFTs.

Keywords: FRP; confinement; concrete; filament-wound tubes; cyclic loading; high-strength concrete; stress-strain behavior

\section{INTRODUCTION}

Concrete-filled FRP tubes (CFFTs) (Mirmiran and Shahawy 1997; Fam and Rizkalla 2001a, b) are an attractive form of hybrid compression members combining FRP and concrete in an optimal manner. A CFFT consists of an outer FRP tube filled with plain or steel-reinforced concrete. The FRP tube is typically manufactured through a filament-winding process (i.e. filament-wound FRP tube). When a concrete-filled FRP tube is under compression, the axially-compressed concrete is also subjected to lateral confinement from the FRP tube which is in tension in the circumferential (or hoop) direction. This lateral confinement from the FRP tube can increase both the strength and the ductility of the concrete significantly. As a result, a highly ductile compression member can be formed from the two brittle materials, namely, FRP and concrete, even when steel reinforcement is completely absent. In addition to excellent ductility and thus excellent seismic resistance, the advantages of CFFTs include their excellent corrosion resistance and the lightweight nature of FRP tubes compared to steel tubes. With these advantages, concrete-filled FRP tubes are attractive for use as bridge columns and piles, both of which are commonly exposed to severe outdoor environments (e.g. sea water). Many studies have been conducted on CFFTs over recent years, and they have been focused on different aspects such as axial compressive behavior (e.g. Mirmiran and Shahawy 1997; Zhang et al. 2000; Fam and Rizkalla 2001a, b; Ozbakkaloglu and Oehlers 
2008), flexural behavior (e.g. Burgueño and Bhide 2006), seismic behavior (e.g. Zhu et al. 2006; Zohrevand and Mirmiran 2013), fatigue behavior (e.g. Ahmad et al. 2008), fire resistance (e.g. Ji et al. 2008), as well as design procedures (e.g. Yu and Teng 2011).

As a structural form with great potential for use in seismic regions, the behavior of CFFTs subject to cyclic loading is of particular importance. The stress-strain behavior of the confined concrete in CFFTs under cyclic axial compression is particularly important for the accurate modeling of such columns under seismic loading. A number of experimental studies (Rousakis 2001; Ilki and Kumbasar 2003; Shao et al. 2006; Lam et al. 2006; Abbasnia and Ziaadiny 2010; Ozbakkaloglu and Akin 2012; Abbasnia et al. 2012, Abbasnia et al. 2013; Bai et al 2013) have been conducted on the cyclic stress-strain behavior of concrete confined by an FRP wrap with fibres oriented in the hoop direction only (referred to as "FRP wrap" hereafter) using cyclic axial compression tests, but no systematic experimental study has been concerned with the confined concrete in CFFTs with a filament-wound FRP tube. To the best of the authors' knowledge, the only existing cyclic axial compression test on concrete-filled filament-wound FRP tubes was conducted by Mirmiran and Shahawy (1997), where only one specimen was tested. The behavior of the concrete in CFFTs is complicated by the significant axial stiffness and Poisson's effect of the FRP tube, and the failure mode of such an FRP tube is also different from that of an FRP wrap with only hoop fibres. In addition, the shrinkage of the concrete infill in CFFTs may lead to a small initial gap between the FRP tube and the concrete, which can also have adverse effects. Against this background, this paper presents an experimental study on the behavior of circular CFFTs under cyclic axial compression. The experimental program included the strength of concrete as a key variable, as CFFTs offer an ideal opportunity for the use of high strength concrete (HSC) because of the confinement from the tube. The experimental program is thus also a much needed supplement to the very 
limited existing research on the cyclic compressive behavior of FRP-confined HSC. Only two studies by Rousakis (2001) and Ozbakkaloglu and Akin (2012) where FRP wraps were used.

\section{EXPERIMENTAL PROGRAM}

\section{Test Specimens}

A total of 15 concrete-filled filament-wound FRP tubes were prepared and tested. All the specimens had a characteristic diameter of $200 \mathrm{~mm}$ (diameter of the concrete core) and a height of $400 \mathrm{~mm}$. These columns were cast in 3 batches (batches 1 to 3) with 3 different concrete mix ratios respectively to produce 3 different concrete grades. Each batch included two groups of specimens which were confined with two different types of filament-wound FRP tubes respectively. Each group included two or three nominally identical specimens among which one was tested under monotonic compression while the other one or two were tested under cyclic compression. For the group with two cyclically loaded specimens, two different loading schemes were used as discussed later. In the preparation of these specimens, the FRP tube was used as the mold for casting the concrete. A $25 \mathrm{~mm}$ wide carbon FRP circumferential strip was added near each end of each CFFT specimen to avoid unexpected failure there.

Each specimen was given a name, which starts with the letter "S" to represent "specimen", followed by a two- or three-digit number to represent the unconfined concrete strength, and then a number which defines the thickness (in mm) of the FRP tube, together with two letters "FW" indicating that the tube is made through a filament-winding process. This is then followed by a letter "M" or "C" to represent "monotonic" or "cyclic" compression. The last number " 1 " or " 2 " in some specimens is used to differentiate two nominally identical 
specimens which were tested under two different cyclic loading schemes respectively. The details of all specimens are summarized in Table 1.

\section{Material Properties}

Self-compacting concrete was used for all the specimens. A previous study by the authors' group (i.e. Yu et al. 2013) has demonstrated that the behavior of FRP-confined self-compacting concrete is generally similar to that of FRP-confined normal concrete. In Batch 1, the concrete was prepared with ordinary Portland cement, fly ash, super plasticizer (S.P.), river sand, and granite aggregate with a maximum nominal size of $10 \mathrm{~mm}$. In Batches 2 and 3, silica fume was added to achieve the high strengths required. The mix proportions used were designed following Lam et al. (1998) and are summarized in Table 2. Three plain concrete cylinders (152.5 mm x $305 \mathrm{~mm}$ ) were tested for each batch to determine the concrete properties. The elastic modulus $\left(E_{c}\right)$, compressive strength $\left(f_{c o}^{\prime}\right)$ and compressive strain at peak stress $\left(\varepsilon_{c o}\right)$ of the concrete averaged from the concrete cylinder tests are given in Table 1.

Three types of prefabricated filament-wound glass FRP (GFRP) tubes were used in the present study. These tubes were manufactured using the same batches of raw materials (i.e. fibres and resin), and were designed to have the same nominal volume fraction and the same angles of fibres (i.e. \pm 80 degrees to the longitudinal axis of the tube respectively), for the same mechanical properties. The only difference among the three types of GFRP tubes is in their thicknesses, which were measured to be $2.2 \mathrm{~mm}, 4.7 \mathrm{~mm}$ and $9.5 \mathrm{~mm}$, respectively. Based on their actual thicknesses, the actual fibre volume fractions in the three types of tubes were found to be slightly different (i.e. $0.452,0.466$ and 0.482 respectively). In the present 
study, only selected tubes were tested under hoop tension and axial compression respectively. Appropriate small adjustments were made to the mechanical properties obtained from tests to consider the difference in the actual fibre volume fraction when these values were used for other types of tubes.

Tensile split-disk tests on 5 FRP rings were conducted following ASTM D2290-08 (2008) as shown in Figure 1. The 5 FRP rings, each having a uniform height of $35 \mathrm{~mm}$, were cut from the same FRP tube with a thickness of $4.7 \mathrm{~mm}$. Six hoop strain gauges with a gauge length of $20 \mathrm{~mm}$ were installed, among which two were centred at the two gaps, whereas the nearer edges of the other four gauges were located at $15 \mathrm{~mm}$ away from the gaps. The readings of the two strain gauges at the gaps were found to be lower due to the effect of bending there. The experimental tensile stress-strain curves are shown in Figure 2, where the tensile stress was obtained by dividing the applied tensile force by two times the cross-section area of the ring, while the tensile strain was averaged from the four hoop strain gauges away from the gaps to eliminate any effects from local bending at the gaps. Figure 2 shows that the FRP tube has a linear stress-strain relationship in the hoop direction. The average rupture strain and secant elastic modulus at failure are $1.49 \%$ and $45.9 \mathrm{GPa}$, respectively.

Compression tests on 5 FRP rings were conducted following GB/T5350-2005 (2005) as shown in Figure 3. The 5 FRP rings all had a height of $60 \mathrm{~mm}$ and were cut from the same FRP tube with a thickness of $9.5 \mathrm{~mm}$. They were tested on an MTS machine with a displacement control rate of $0.036 \mathrm{~mm} / \mathrm{min}$. Figure 4 shows the experimental stress-strain curves. The stress is shown to increase linearly with the strain until an axial strain of around 0.004, after which the FRP tube segment exhibits significantly nonlinear behavior before the final failure of the tube segment due mainly to failure of the resin matrix. The average secant 
elastic modulus at an axial strain of 0.004 , which represents the slope of the approximately linear initial portion, was found to be $15.6 \mathrm{GPa}$ and is referred to as $E_{\text {sec } 1}$. The average ultimate axial stress, ultimate axial strain and secant elastic modulus at failure (referred to as $\left.E_{s e c 2}\right)$ are $95.1 \mathrm{MPa}, 0.95 \%$ and $10.0 \mathrm{GPa}$ respectively. The large difference between $E_{\text {sec } 1}$ and $E_{\text {sec } 2}$ indicates the significant nonlinearity of the stress-strain curves.

\section{Experimental Set-up and Instrumentation}

For each specimen, eight axial strain gauges, among which four had a gauge length of $20 \mathrm{~mm}$ while the other four had a gauge length of $100 \mathrm{~mm}$, were installed at the mid-height of the FRP tube (Figure 5). The use of two different gauge lengths was to clarify any possible effect of the gauge length on the measured axial strains. Three groups of hoop strain gauges with a gauge length of $20 \mathrm{~mm}$ were installed at 3 different heights of the FRP tube respectively: mid-height; $100 \mathrm{~mm}$ lower than the mid-height; $100 \mathrm{~mm}$ higher than the mid-height. Each group included four hoop strain gauges evenly distributed over the circumference (Figure 5). In addition, 4 LVDTs were used to obtain the total axial shortening of each specimen. All compression tests were carried out using a column testing facility with a displacement control rate of $0.24 \mathrm{~mm} / \mathrm{min}$. The axial load was applied on both the FRP tube and the concrete simultaneously. All test data, including the strains, loads, and displacements, were recorded simultaneously by a data logger.

\section{Loading Scheme}

For the groups (i.e. S54-2FW, S54-4FW and S104-4FW) with two cyclically loaded specimens, one was subjected to type C1 loading while the other was subjected to type C2 
loading. Both the type C1 and type C2 loading schemes were designed for full unloading/reloading cycles where the unloading of each cycle was terminated at a zero load and the reloading of each cycle was terminated at the unloading displacement of the same cycle (i.e. where the unloading starts) or after reaching the envelope curve. For type C1 loading, a single unloading/reloading cycle was applied at each of several prescribed unloading displacement values before failure. For type C2 loading, a number (9-12) of repeated unloading/reloading cycles were applied at a single prescribed unloading displacement value (see Table 3). For the groups (i.e. S84-4FW, S84-9FW and S104-9FW) with only one cyclically loaded specimen, the specimen was subjected to a combination of type C1 and C2 loading: a single unloading/reloading cycle was applied at each of the first several prescribed unloading displacement values while a number (9-12) of repeated cycles were applied at the last prescribed unloading displacement value. All the loading schemes were executed manually with the use of the displacement averaged from the 4 LVDTs (Figure 5) and the load readings of the column testing facility as the controlling parameters. Details of the loading schemes are summarized in Table 3.

\section{TEST RESULTS AND DISCUSSIONS}

\section{Test Observations}

All the specimens were tested to failure except for the specimens with a $9 \mathrm{~mm}$ FRP tube (i.e. groups S84-9FW and S104-9FW). The tests for these specimens were terminated at an axial load of $8000 \mathrm{kN}$ because of the loading capacity limitation of the column testing facility. Typical failed specimens (i.e. specimens S54-2FW-C2 and S84-4FW-C) are shown in Figure 6. 
The failure processes of all other specimens were similar, indicating that different loading schemes had little effect on this process. As the loading process progressed, white patches along the fibre directions appeared on the outer surface of the tube, indicating local damage in the resin because of the dilation of the concrete inside. These white patches normally started to appear after the axial strain exceeded $\varepsilon_{c o}$, and developed continuously until the rupture of fibres which occurred nearby. It is worth noting that the rupture of fibres, starting from the outermost ply, was a progressive process accompanied with continuous snapping noises. This is different from the sudden failure of concrete confined with a wet-layup FRP wrap with unidirectional fibres in the hoop direction.

\section{Axial Strain}

There are three ways to obtain the axial strain of a specimen: (1) the average reading from the four $20 \mathrm{~mm}$ axial strain gauges at the mid-height (referred to as the SG-20 axial strain); (2) the average reading from the four $100 \mathrm{~mm}$ axial strain gauges at the mid-height (referred to as the SG-100 axial strain); and (3) the average strain over the whole height of the specimen based on the average overall axial shortening of the three LVDTs (referred to as the nominal axial strain).

Figure 7 shows a comparison between the axial strains obtained in the three different ways for the specimens tested under axial monotonic compression. The SG-20 and the SG-100 axial strains shown in Figure 7 were all averaged from the readings of four axial strain gauges except for specimen S104-9FW-M. In specimen S104-9FW-M, one of the $100 \mathrm{~mm}$ axial strain gauges was damaged, so the SG-100 strains for this specimen were from the three surviving axial strain gauges. Figure 7a shows that the SG-20 and the SG-100 axial strains 
are generally in close agreement. For the specimens with the lowest concrete strength (i.e. specimens in the S54 series), the nominal axial strain also agrees closely with the SG-20 and the SG-100 axial strains (Figures 7b and 7c). However, for the specimens in the other two series (i.e. specimens in the S84 and S104 series), such agreement is only observed before a threshold strain value (around 0.004 for the S84 series and around 0.005 for the S104 series), beyond which the nominal axial strain becomes significantly larger than the axial strain gauge readings (i.e. both the SG-20 and the SG-100 strains), indicating that significant localized deformation occurred outside the $100 \mathrm{~mm}$ mid-height region of the column. This observation is probably due to the brittleness of HSC, which led to more localized and non-uniform damage of concrete.

As the axial strain gauges were attached on the external surface of the FRP tube, and significant slips may have existed between the FRP tube and the concrete especially after the development of significant localized deformation of concrete, the axial strain gauge readings cannot simply be assumed to closely reflect the strain state of the confined concrete. In the subsequent sections, the nominal axial strain is used to represent the axial strain of the confined concrete. It should be noted that the nominal axial strain represents the average deformation of the concrete over the column height, where the deformation near the ends is expected to be different from that near the mid-height because of the lateral constraints from the two ends. The existence of such differences, as well as the other possible deformation of the loading system, generally leads to slightly larger strains as measured by LVDTs especially in the initial stage of loading. However, this effect is believed to be small, given the fact that the nominal axial strain agrees closely with the mid-height axial strain gauge reading for the specimens in the S54 series (Figure 7). 


\section{Hoop Strain}

Making use of readings from the three groups of hoop strain gauges located at 3 different heights of the FRP tube, the hoop strain distributions at the ultimate state of all the 15 specimens are shown in Figure 8, except for specimens in groups S84-9FW and S104-9FW which were not tested to failure as mentioned earlier. For these specimens, the hoop strains at the time when the tests were terminated are shown in Figure 8. It is evident that a considerable scatter exists in the hoop strain readings. Such scatters appear to be less pronounced for the mid-height section than the other two sections (sections 1 and 3 in Figure 5), indicating that the lateral expansion of concrete is more uniform in the mid-height region. While the maximum hoop strain and the minimum hoop strain were found to be typically not at the mid-height section, the average hoop strain reading at the mid-height section $\left(\varepsilon_{h, \text { rup } 2}\right)$ is very close to and generally slightly higher than the average reading of the three groups of hoop strain gauges $\left(\varepsilon_{h, \text { rup } 1}\right)$ (see Table 4$)$. The average hoop rupture strain appears to be smaller for specimens with a higher concrete strength and/or a weaker tube.

\section{Axial Load-Axial Strain Behavior}

The key test results of all 15 specimens are summarized in Table 4 . In this table, $F_{\text {all }}$ is the peak axial load of the specimen from the test; $F_{c}$ is the peak axial load taken by the

concrete; $f_{c c}^{\prime}$ is the peak axial stress of the confined concrete; $\varepsilon_{c u}$ is the ultimate axial strain of the concrete at the rupture of the FRP tube. The peak stress $f_{c o}^{\prime}$ and the strain at peak stress $\varepsilon_{c o}$ of unconfined concrete are used to normalize the ultimate axial stress and the ultimate axial strain, respectively. 
Typical axial load-axial strain curves of the CFFT specimens are shown in Figure 9. Figure 9 shows that all the specimens had an approximately bilinear load-strain curve (for monotonically loaded specimens) or envelope curve (for cyclically loaded specimens), but for some specimens with a very high strength concrete (e.g. specimen S104-4FW-M), there is a slight drop in the load in the transition zone between the two approximately linear portions of the curve. Such a slight load drop, however, was not found in specimens with a relatively low concrete strength (e.g. specimen S54-2FW-M), or specimens with a very strong FRP tube (e.g. specimen S104-9FW-M). It is thus believed that such a load drop is due to the brittleness of HSC when it is subjected to insufficient confinement. It does not appear to be caused by the less intimate contact between the concrete and the FRP tube in a CFFT, as such a load drop is also a common observation in HSC confined with an FRP wrap (Cui and Sheikh 2009; Ozbakkaloglu and Akin 2012).

\section{Axial Stress-Axial Strain Curves of Concrete}

The axial stress-strain curves of the FRP-confined concrete in CFFTs are shown in Figure 10 for all the specimens, where those of cyclically loaded specimens are compared with the curve of the corresponding specimen under monotonic compression. The axial stress of the concrete was found as the load carried by the concrete section divided by its cross-sectional area. The load carried by the concrete section is assumed to be equal to the difference between the load carried by the specimen and the load carried by the FRP tube at the same axial strain. One main difference between the FRP tube in a CFFT and an FRP wrap is that the former generally has a considerable axial stiffness and its direct contribution to the axial load capacity cannot be ignored. In the present study, the load carried by the FRP tube in 
CFFTs was found from axial compression tests on hollow FRP tubes. When the axial strain of a specimen exceeds the ultimate strain of the corresponding hollow FRP tube tests, it is assumed that the load resisted by the FRP tube is equal to its ultimate load because of the support from the concrete core (Figure 9a). It is further assumed that in the unloading process, the load taken by the FRP tube reduces proportionally to the total axial load acting on the specimen, and reaches zero at the same time as the total load becomes zero (Figure 9b). While these assumptions may lead to small errors in the estimated load taken by the FRP tube, such small errors are believed to have negligible effects on the obtained axial stress-strain curve of the confined concrete, due to the much smaller cross-sectional area of the FRP tube.

It is evident from Figure 10 that the envelope curves of all the specimens subjected to cyclic axial compression are almost the same as the corresponding monotonic axial stress-strain curves. This observation is consistent with that from Lam et al.'s (2006) tests on FRP-confined NSC, where FRP wraps formed via a wet-layup process were used. Similar to the axial load-strain curves, Figure 10 also shows that all the monotonic stress-strain curves have an approximately bilinear shape with a second ascending branch, except for the specimens with HSC and a $4.0 \mathrm{~mm}$ GFRP tube (i.e. S84-4FW-M and S104-4FW-M). For these two specimens, there is a slight fluctuation in the stress-strain curve at an axial strain of around 0.006, which is associated with a sudden increase in the hoop strain (Figure 11). This phenomenon, as discussed above, is believed to be due to the brittleness of HSC and the use of a FRP tube which is not sufficiently stiff in the circumferential direction.

Figure 10 also shows that the cyclic stress-strain curves of concrete in CFFTs possess the following key characteristics, which are the same as those of concrete confined with an FRP wrap (Lam and Teng 2009): (1) the loading history has a cumulative effect on both the plastic 
strain and stress deterioration; (2) the unloading path is generally nonlinear with a continuously decreasing slope while the reloading path is approximately linear.

\section{COMPARISON WITH EXISTING STRESS-STRAIN MODELS}

\section{General}

It has been shown in Figure 10 that the envelope curves of specimens subjected to cyclic axial compression are almost the same as the axial stress-strain curves of the corresponding specimens subjected to monotonic compression. In this section, the experimental envelope stress-strain curves are compared with predictions from an accurate monotonic stress-strain model proposed by Teng et al. (2009). Teng et al.'s (2009) model is a refined version of a well-recognized model developed by the same research group (Lam and Teng 2003). The test database, on which Lam and Teng’s (2003) and Teng et al.'s (2009) models have been based, is however generally limited to normal strength concrete (with only one group of specimens having the maximum unconfined strength of 55.2 MPa) and concrete confined with an FRP wrap. The comparison presented in this section thus allows a quantitative assessment of the differences which may be caused by the use of HSC and/or a filament-wound tube in the monotonic behavior of FRP-confined concrete.

The experimental results are also compared with a cyclic stress-strain model proposed by Lam and Teng (2009), which is again based on test results of concrete confined with an FRP wrap. Lam and Teng (2009) mentioned that their model is expected to be applicable to HSC in terms of the unloading/reloading paths, but the calibration of the model for HSC was based on limited test data from one single study (i.e. Rousakis 2001). The comparison presented in this section thus allows further examination of the applicability of this model to HSC and 
when HSC is confined by an FRP tube. It should be noted that in Lam and Teng (2009), Lam and Teng's (2003) stress-strain model is used to predict the envelope stress-strain curve. In the present study, the comparison with Lam and Teng's (2009) model is limited to the unloading/reloading paths.

\section{Comparison with Teng et al.’s (2009) Model}

Teng et al.'s (2009) model

Teng et al.'s (2009) model consists of a parabolic first portion and a linear second portion. Compared with Lam and Teng's (2003) model, the 2009 model includes more accurate expressions for the ultimate axial strain and the compressive strength. These new expressions allow the effects of confinement stiffness and the jacket strain capacity to be separately reflected and account for the effect of confinement stiffness explicitly instead of reflecting it through the confinement ratio. Readers may refer to Teng et al. (2009) for more details of the model. It should be noted that Teng et al. (2009) proposed two versions of the model, but both versions predict the same stress-strain curves for concrete without a descending branch in the stress-strain curve. Predictions of the two versions are thus the same for the specimens tested in the present study.

\section{Comparison}

Comparisons between the predictions of Teng et al.'s (2009) model and the test results are given in Figure 12. In making the predictions, the material properties summarized in Table 1

were used and $\varepsilon_{h, \text { rup } 1}$ was adopted as the FRP hoop rupture strain. It is evident that the predictions agree very well with the experimental results except for the initial slope for some 
specimens. The difference in the initial slope is due to the use of strains calculated from the total axial shortenings (i.e. LVDT readings) in establishing the experimental curves. As explained earlier, the strains from LVDTs are generally larger than those at mid-height in the initial stage of loading. If the actual axial strains of concrete at mid-height are used, it can be expected that the predicted initial slopes will be in closer agreement with the experimental results.

The above comparison suggests that there is no obvious difference between the stress-strain behavior of concrete confined with an FRP wrap and that in a CFFT. The comparison also suggests that Teng et al.'s (2009) model, although developed based on test data of normal strength concrete, can provide accurate predictions for FRP-confined HSC with sufficient confinement. Despite the overall good performance of Teng et al.'s (2009) model for HSC, it is also noted that this model fails to predict the slight stress drop in the transition zone between the two portions of the stress-strain curve for some specimens (e.g. Figures 12b and 12c). Considering that the magnitude of this stress drop may become greater when the circumferential stiffness of the confining FRP wrap/tube becomes smaller (Cui and Sheikh 2009; Ozbakkaloglu and Akin 2012), the applicability of Teng et al.’s (2009) model needs to be further examined for HSC confined by a weak FRP wrap/tube.

\section{Comparison with Lam and Teng's (2009) Model}

$\underline{\text { Lam and Teng's (2009) model }}$

Lam and Teng's (2009) model provides explicit equations to describe the cyclic stress-strain history of FRP-confined concrete. In Lam and Teng's (2009) model, the unloading curves, being the paths experienced by the concrete when its strain reduces, can be divided into 
envelope unloading paths (i.e. unloading paths starting from the envelope curve) and internal unloading paths (i.e. the previous reloading path does not reach the envelope curve). Envelope unloading paths depend only on the unloading stress and the unloading strain, while internal unloading paths depend also on the prior loading history. The reloading curves, being the paths experienced by the concrete when its strain increases, may or may not reach the envelope curve. When unloading/reloading cycles are repeated within the envelope curve, they are defined as internal cycles and are numbered so that the effects of previous internal cycles on subsequent cycles can be considered.

In Lam and Teng's (2009) model, empirical equations are also given for the key parameters determining unloading/reloading curves, including the stress deterioration rule and the plastic strain which is defined as the strain value at the intersection of an unloading path and the strain axis. The cumulative effect of the loading history is considered in these equations. Readers may refer to Lam and Teng (2009) for more details of the model.

\section{$\underline{\text { Comparison }}$}

Predictions from Lam and Teng's (2009) model are compared with the present test results in terms of the envelope unloading/reloading behavior in Figure 13. In making the predictions, the experimental envelope curves were used together with Lam and Teng's (2009) model, so that any difference between the predictions and the experimental unloading/reloading cycles comes only from the cyclic stress-strain model.

Figure 13 shows that predictions from Lam and Teng's (2009) model generally deviate from the experimental results, and it is evident that such deviations become much more 
pronounced for concrete with a higher strength. Considering that the predictions for the S54 series still appear to be reasonable, it may be concluded that Lam and Teng's (2009) model is applicable to normal strength concrete filled FRP tubes, but not CFFTs with HSC. This is probably due to the fact that the development of Lam and Teng's (2009) model relied heavily on the experimental results by Lam et al. (2006) which only covered a small range of concrete strengths (i.e. $38.9 \mathrm{MPa}$ and $41.1 \mathrm{MPa}$ ). A recent experimental study by Ozbakkaloglu and Akin (2012), where concrete cylinders confined with an FRP wrap were tested under cyclic axial compression, also showed that the performance of Lam and Teng's (2009) model for HSC is not as good as its performance for normal strength concrete. Apparently, revisions are needed before Lam and Teng's (2009) model can accurately predict the envelope unloading/reloading curves of FRP-confined HSC.

Predictions from Lam and Teng's (2009) model are compared with the present test results in terms of the repeated unloading/reloading cycles in Figure 14. For a clearer comparison, each experimental cycle was plotted against the prediction individually. Only comparisons for the $1^{\text {st }}, 4^{\text {th }}, 7^{\text {th }}$ and the last cycles are shown in Figure 14 , as comparisons for other cycles are similar. In making the predictions, the envelope unloading strain $\varepsilon_{u n, e n v}$ and the envelope unloading stress $\sigma_{u n, e n v}$, as well as the experimental plastic strains of envelope cycles $\varepsilon_{p l, 1}$ were used so that the comparisons in Figure 14 reflect only the accuracy of the model for predicting the cumulative effect of loading history. It is evident that Lam and Teng's (2009) model generally provides reasonable predictions, but the performance of the model becomes slightly worse for specimens with a higher concrete strength.

\section{CONCLUSIONS}


This paper has presented an experimental study on the cyclic axial behavior of CFFTs, where the strength of concrete is a key variable. The test results have also been compared with a monotonic stress-strain model and a cyclic stress-strain model, both of which have been based on test databases which are limited to concrete confined with an FRP wrap and include only a small number of tests for HSC. The results and discussions allow the following conclusions to be drawn:

(1) The rupture of fibres in a filament-wound FRP tube, starting from the outermost ply, is a progressive process which is different from the failure of concrete confined with an FRP wrap.

(2) The cyclic axial stress-strain behavior of concrete in CFFTs is generally similar to that of concrete confined with an FRP wrap.

(3) Teng et al.'s (2009) monotonic stress-strain model is capable of providing accurate predictions for HSC in CFFTs, given that the FRP tube has a sufficient circumferential stiffness.

(4) Lam and Teng's (2009) cyclic stress-strain model may be applicable to normal strength concrete in CFFTs, but not HSC in CFFTs.

\section{ACKNOWLEDGEMENTS}

The work has been supported by the Natural Science Foundation of China (Project No. 51108096), the Hong Kong Research Grants Council (Project No.: 528510) as well as the Australian Research Council through a Discovery Early Career Researcher Award (Project ID: DE140101349) for the second author. 


\section{REFERENCES}

Abbasnia, R. and Ziaadiny, H. (2010) "Behavior of concrete prisms confined with FRP composites under axial cyclic Compression.” Engineering Structures, 32, 648-665.

Abbasnia, R., Ahmadi, R. and Ziaadiny, H. (2012) “Effect of confinement level, aspect ratio and concrete strength on the cyclic stress-strain behavior of FRP-confined concrete prisms.” Composites Part B: Engineering, 43, 825-831.

Abbasnia, R., Hosseinpour, F., Rostamian, M. and Ziaadiny, H. (2013) "Cyclic and monotonic behavior of FRP confined concrete rectangular prisms with different aspect ratios.” Construction and Building Materials. 40, 118-125.

Ahmad, I., Zhu, Z. Y., Mirmiran, A. and Fam, A. Z. (2005). Shear strength prediction of deep CFFT beams", ACI Special Publication SP-230-61 (CD-ROM), 1085-1102.

ASTM D2290-08 (2008). Standard Test Method for Apparent Hoop Tensile Strength of Plastic or Reinforced Plastic Pipe by Split Disk Method, American Society for Testing and Materials (ASTM), Philadelphia, USA.

Bai, Y.L., Dai, J.G. and Teng, J.G. (2013) “Cyclic compressive behavior of concrete confined with large rupture strain FRP composites”, Journal of Composites for Construction, ASCE, 18(1).

Burgueño, R. and K. Bhide (2006). "Shear response of concrete-filled FRP composite cylindrical shells.” Journal of Structural Engineering, ASCE, 132(6), 949-960.

Cui, C. and S. Sheikh (2010). "Experimental study of normal- and high-strength concrete confined with fiber-reinforced polymers.” Journal of Composites for Construction, ASCE, 14(5), 553-561.

Fam, A. Z. and Rizkalla, S. H. (2001a). “Confinement model for axially loaded concrete 
confined by circular fiber-reinforced polymer tubes.” ACI Structural Journal, 98(4), $451-461$.

Fam, A.Z. and Rizkalla, S.H. (2001b). "Behavior of axially loaded concrete-filled circular fiber-reinforced polymer tubes”, ACI Structural Journal, 98(3), 280-289.

GB/T5350-2005 (2005). Fiber-Reinforced Thermosetting Plastic Composites Pipe: Determination for Longitudinal Compressive Properties, The Standards Press of China.

Ilki, A. and Kumbasar, N. (2003). “Compressive behavior of carbon fiber composite jacketed concrete with circular and non-circular cross sections.” Journal of Earthquake Engineering, 7(3), 381-406.

Ji, G., Li, G., Li, X., Pang, S. and Jones, R. (2008). “Experimental study of FRP tube encased concrete cylinders exposed to fire.” Composite Structures, 85(2), 149-154.

Lam, L., Wong, Y.L. and Poon, C.S. (1998). "Effect of fly ash and silica fume on compressive and fracture behaviors of concrete.” Cement and Concrete Research, 28(2), 271-283.

Lam, L. and Teng, J. G. (2003). "Design-oriented stress-strain model for FRP-confined concrete." Construction and Building Materials, 17(6-7), 471-489.

Lam, L., Teng, J. G., Cheung, C.H. and Xiao, Y. (2006). “FRP-confined concrete under axial cyclic compression.” Cement \& Concrete Composites, 28, 949-958.

Lam, L. and Teng, J. G. (2009). "Stress-strain model for FRP-confined concrete under cyclic axial compression.” Engineering Structures, 31(2), 308-321.

Mirmiran, A. and Shahawy, M. (1997). "Behavior of concrete columns confined by fiber composites.” Journal of Structure Engineering, ASCE, 123(5), 583-590.

Ozbakkaloglu, T. and Akin, E.. (2012) "Behavior of FRP-confined normal-and high-strength concrete under cyclic axial compression.” Journal of Composites for Construction, ASCE, 16, 451-463. 
Ozbakkaloglu, T. and D. Oehlers (2008). “Concrete-filled square and rectangular FRP tubes under axial compression.” Journal of Composites for Construction, ASCE, 12(4), 469-477.

Rousakis, T. C. (2001). Experimental Investigation of Concrete Cylinders Confined by Carbon FRP Sheets Under Monotonic and Cyclic Axial Compression Load, Research Report. 01:2, Division of Building Technology, Chalmers University of Technology, Gothenburg, Sweden.

Shao, Y., Zhu, Z. and Mirmiran, A. (2006). “Cyclic modeling of FRP confined concrete with improved ductility.” Cement and Concrete Composites, 28(10), 959-968.

Teng, J. G., Jiang, T., Lam, L. and Luo, Y. Z. (2009). "Refinement of a design-oriented stress-strain model for FRP-confined concrete.” Journal of Composites for Construction, ASCE, 13(4), 269-278.

Wang, Z.Y., Wang, D.Y., Simth, S.T. and Lu, D.G. (2012) "Experimental testing and analytical modeling of CFRP-confined large circular RC columns subjected to cyclic axial compression”, Engineering Structures, 40, 67-74.

Yu, T. and Teng, J.G. (2011). "Design of concrete-filled FRP tubular columns: provisions in the Chinese technical code for infrastructure application of FRP composites”, Journal of Composites for Construction, ASCE, 15(3), 451-461.

Yu, T., Fang, X.L. and Teng, J.G. (2013). “FRP-confined self-compacting concrete under axial compression”, Journal of Materials in Civil Engineering, ASCE, in press.

Zhang, D.X., Huang, L.N., Wang, R.G. and Zhao, J.H. (2000). “Experimental research on the mechanical properties of concrete filled FRP tubular column”, Journal of Harbin University of Civil Engineering and Architecture, 1(33), 73-76 (in Chinese).

Zhu, Z., Ahmad, I., Mirmiran, A. (2006). "Seismic performance of concrete-filled FRP tube columns for bridge substructure.” Journal of Bridge Engineering, ASCE, 11(3), 359-370. 
Zohrevand, P. and A. Mirmiran (2013). "Seismic response of ultra-high performance concrete-filled FRP tube columns.” Journal of Earthquake Engineering, 17(1), 155-170. 
Click here to download Table: Experiment_FCSCs_Cyclic_Table_Revised_Final.docx

Table 1: Details of Specimens

\begin{tabular}{|c|c|c|c|c|c|}
\hline \multirow[b]{2}{*}{ Specimen } & \multirow{2}{*}{$\begin{array}{l}\text { Loading } \\
\text { Type }\end{array}$} & \multirow{2}{*}{$\begin{array}{c}\text { FRP tube thickness } \\
t_{f r p} \quad(\mathrm{~mm})\end{array}$} & \multicolumn{3}{|c|}{ Concrete Properties } \\
\hline & & & $f_{c o}^{\prime}(\mathrm{MPa})$ & $E_{c}(\mathrm{GPa})$ & $\varepsilon_{c o}(\%)$ \\
\hline $\begin{array}{c}\text { S54-2FW-M } \\
\text { S54-2FW-C1,2 } \\
\text { S54-4FW-M } \\
\text { S54-4FW-C1,2 }\end{array}$ & $\begin{array}{l}\text { Monotonic } \\
\text { Cyclic } \\
\text { Monotonic } \\
\text { Cyclic }\end{array}$ & 4.7 & $\begin{array}{c}\text { Batch-1 } \\
54.1\end{array}$ & 27.8 & 0.251 \\
\hline $\begin{array}{l}\text { S84-4FW-M } \\
\text { S84-4FW-C } \\
\text { S84-9FW-M } \\
\text { S84-9FW-C }\end{array}$ & $\begin{array}{l}\text { Monotonic } \\
\text { Cyclic } \\
\text { Monotonic } \\
\text { Cyclic }\end{array}$ & 9.5 & $\begin{array}{c}\text { Batch-2 } \\
84.6\end{array}$ & 33.1 & 0.275 \\
\hline $\begin{array}{l}\text { S104-4FW-M } \\
\text { S104-4FW-C1,2 } \\
\text { S104-9FW-M } \\
\text { S104-9FW-C }\end{array}$ & $\begin{array}{l}\text { Monotonic } \\
\text { Cyclic } \\
\text { Monotonic } \\
\text { Cyclic }\end{array}$ & 9.5 & $\begin{array}{c}\text { Batch-3 } \\
104.4\end{array}$ & 36.5 & 0.311 \\
\hline
\end{tabular}


Table 2: Mix proportions of concrete

\begin{tabular}{ccccccccc}
\hline \multirow{2}{*}{$\begin{array}{c}\text { Specimen } \\
\text { batch }\end{array}$} & $\begin{array}{c}\text { Water } \\
\text { cement } \\
\text { ratio }\end{array}$ & Water & Cement & Fly ash & $\begin{array}{c}\text { Silica } \\
\text { fume }\end{array}$ & $\begin{array}{c}\text { Super } \\
\text { plasticizer* }\end{array}$ & $\begin{array}{c}\text { Coarse } \\
\text { aggregate }\end{array}$ & Sand \\
\cline { 3 - 8 } & & & & $\left(\mathrm{kg} / \mathrm{m}^{3}\right)$ & & & \\
\hline Batch-1 & 0.35 & 175 & 300 & 200 & --- & 9 & 829 & 796 \\
Batch-2 & 0.29 & 174 & 377 & 203 & 29 & 11 & 793 & 762 \\
Batch-3 & 0.23 & 155 & 442 & 170 & 68 & 16 & 819 & 712 \\
\hline
\end{tabular}

*The brand of the super plasticizer is "Grace HK", and the product model is "ADVA109". 
Table 3: Loading schemes for specimens under cyclic axial compression

\begin{tabular}{cccccccccc}
\hline \multirow{2}{*}{ Specimen } & \multicolumn{8}{c}{ Unloading displacement $(\mathrm{mm})$ found from LVDTs } \\
& Step 1 & Step 2 & Step 3 & Step 4 & Step 5 & Step 6 & Step 7 & Step 8 & Step 9 \\
\hline S54-2FW-C1 & 0.94 & 1.94 & 2.91 & 3.92 & 4.91 & 5.93 & 6.94 & --- & --- \\
S54-2FW-C2 & $5.96(10) *$ & --- & --- & --- & --- & --- & --- & --- & --- \\
S54-4FW-C1 & 1.09 & 2.01 & 4.09 & 6.11 & 8.13 & 10.11 & 12.09 & 14.12 & 16.18 \\
S54-4FW-C2 & $12.14(10)^{*}$ & --- & --- & --- & --- & --- & --- & --- & --- \\
\hline S84-4FW-C & 1.05 & 2.07 & 3.13 & 4.26 & 5.10 & $6.27(11) *$ & --- & --- & --- \\
S84-9FW-C & 1.03 & 2.03 & 4.09 & 6.20 & 8.42 & $10.43(9) *$ & --- & --- & --- \\
\hline S104-4FW -C1 & 1.03 & 1.97 & 2.95 & 4.11 & 5.13 & 6.10 & 7.10 & 8.22 & 9.49 \\
S104-4FW -C2 & $7.05(12) *$ & --- & --- & --- & --- & --- & --- & --- & --- \\
S104-9FW-C & 1.03 & 2.02 & 4.07 & 6.08 & $8.47(10) *$ & --- & --- & --- & --- \\
\hline
\end{tabular}

*The number in the bracket is the number of repeated cycles imposed at that prescribed unloading displacement. 
Table 4: Key test results

\begin{tabular}{ccccccccc}
\hline \multirow{2}{*}{ Specimen } & $F_{\text {all }}$ & $F_{c}$ & $f_{c c}^{\prime}$ & $\varepsilon_{c u}$ & $\frac{f_{c c}^{\prime}}{f_{c o}}$ & $\frac{\varepsilon_{c u}}{\varepsilon_{c o}}$ & $\varepsilon_{h, r u p 1}$ & $\varepsilon_{h, r u p 2}$ \\
& $(\mathrm{kN})$ & $(\mathrm{kN})$ & $(\mathrm{MPa})$ & $(\%)$ & $(\%)$ \\
\hline S54-2FW-M & 3312 & 3179 & 101.3 & 2.25 & 1.87 & 8.73 & 1.43 & 1.61 \\
S54-2FW-C1 & 2833 & 2700 & 86.0 & 1.76 & 1.59 & 6.83 & 1.08 & 1.12 \\
S54-2FW-C2 & 2917 & 2785 & 88.7 & 1.89 & 1.64 & 7.33 & 1.11 & 1.18 \\
S54-4FW-M & 5734 & 5447 & 173.5 & 4.93 & 3.21 & 19.1 & 1.95 & 2.01 \\
S54-4FW-C1 & 5366 & 5078 & 161.7 & 4.42 & 2.99 & 17.2 & 1.68 & 1.82 \\
S54-4FW-C2 & 5294 & 5006 & 159.4 & 4.43 & 2.95 & 17.2 & 1.69 & 1.76 \\
\hline S84-4FW-M & 5189 & 4901 & 156.1 & 2.20 & 1.85 & 8.00 & 1.17 & 1.27 \\
S84-4FW-C & 5069 & 4782 & 152.3 & 2.39 & 1.80 & 8.69 & 1.10 & 1.08 \\
S84-9FW-M & 8011 & 7417 & 236.2 & 3.17 & 2.79 & 11.5 & 1.12 & 1.21 \\
S84-9FW-C & 8012 & 7418 & 236.2 & 3.22 & 2.79 & 11.7 & 1.05 & 1.18 \\
\hline S104-4FW-M1 & 6215 & 5927 & 188.8 & 2.64 & 1.81 & 8.48 & 1.19 & 1.21 \\
S104-4FW-C1 & 5927 & 5640 & 179.6 & 2.58 & 1.72 & 8.29 & 1.32 & 1.44 \\
S104-4FW-C2 & 5551 & 5263 & 167.6 & 2.38 & 1.61 & 7.64 & 1.09 & 1.13 \\
S104-9FW-M & 8019 & 7424 & 236.4 & 2.61 & 2.26 & 8.38 & 0.94 & 0.91 \\
S104-9FW-C & 8019 & 7424 & 236.4 & 2.61 & 2.26 & 8.38 & 0.93 & 0.91 \\
\hline
\end{tabular}



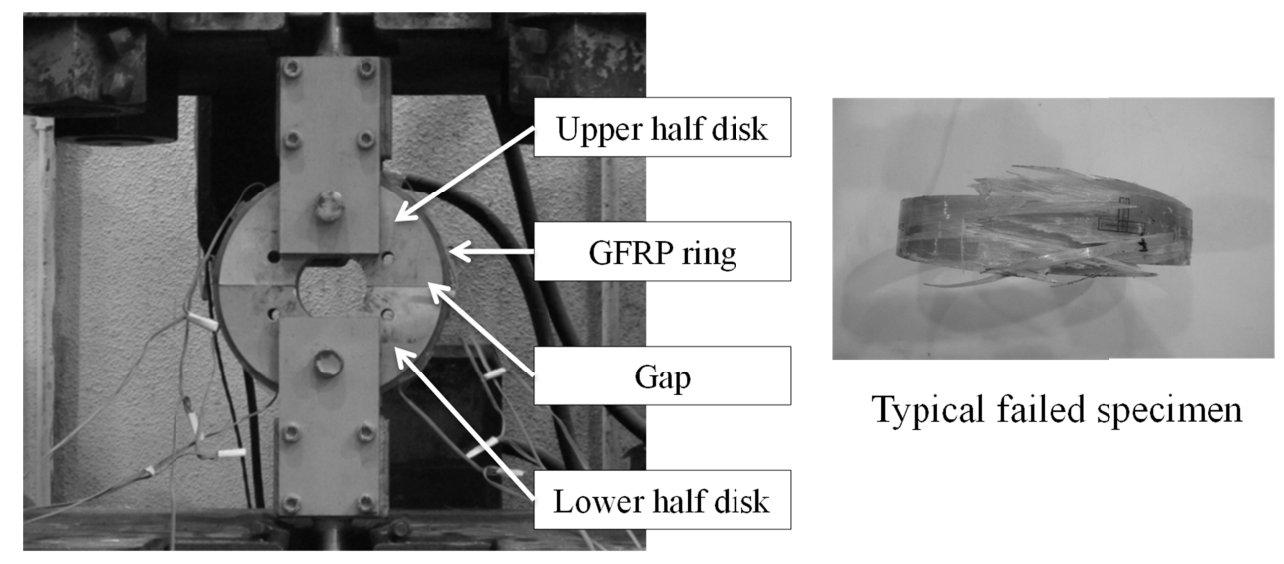

Typical failed specimen

Figure 1: Tensile split-disk test of FRP tubes 


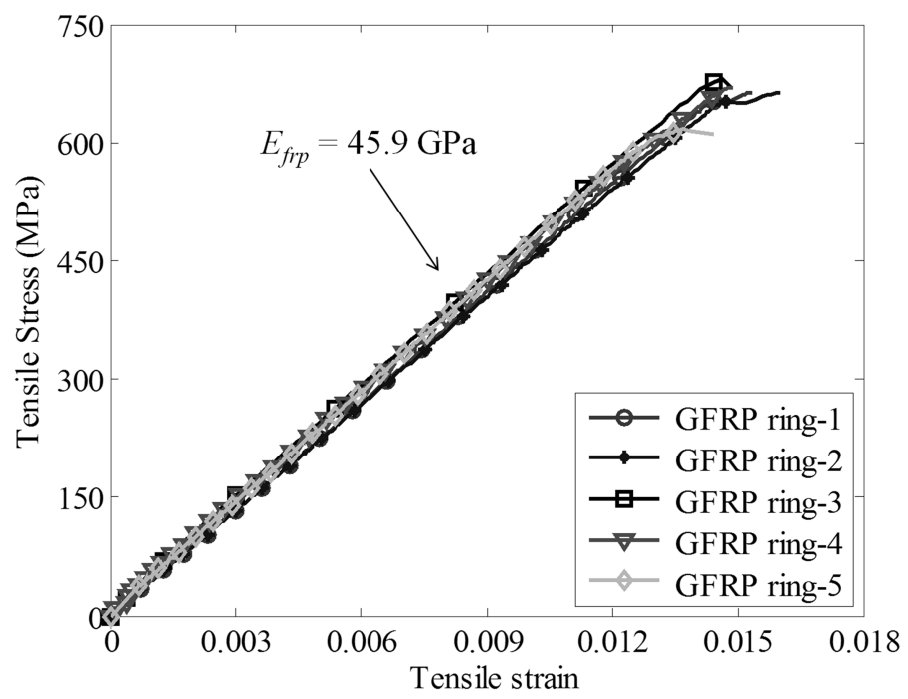

Figure 2: Tensile stress-strain curves of FRP tubes in the hoop direction 


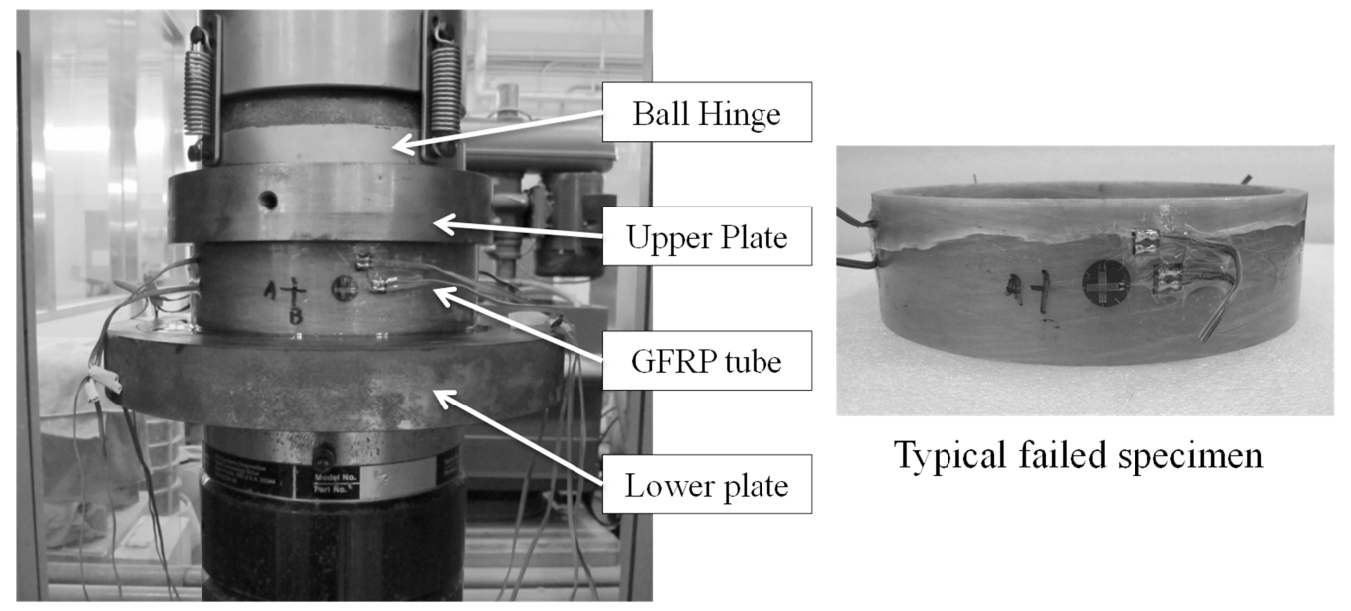

Figure 3: Compression test of FRP tube segment 


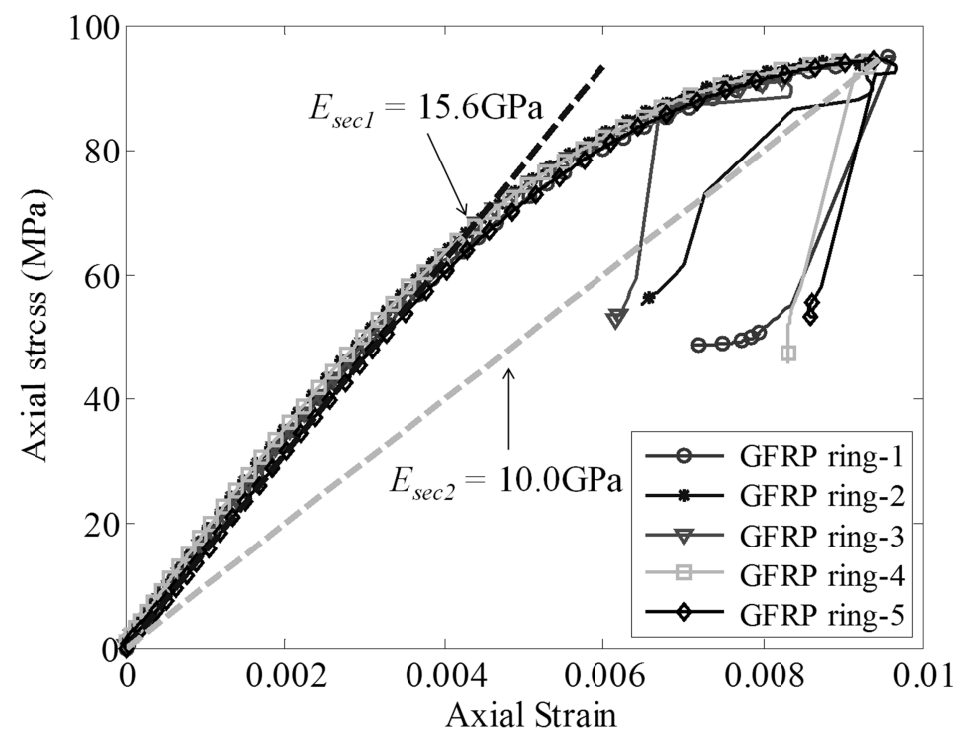

Figure 4: Axial stress-strain curves of FRP tubes under axial compression 


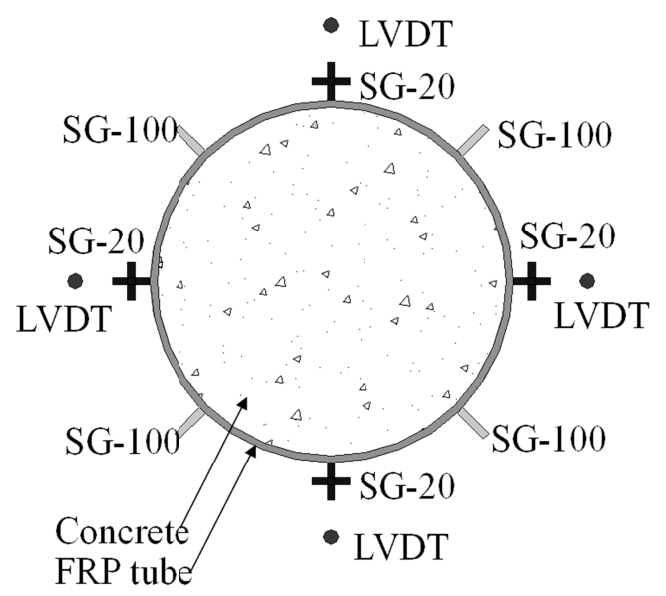

Planar view of strain gauges and LVDTs

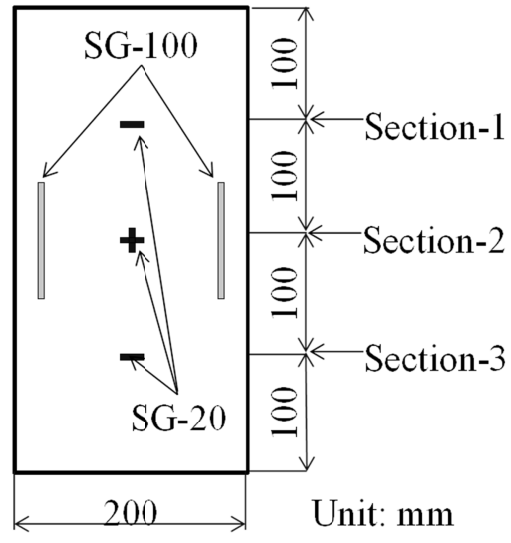

Side view of strain gauges

Figure 5: Experimental set-up and instrumentation 


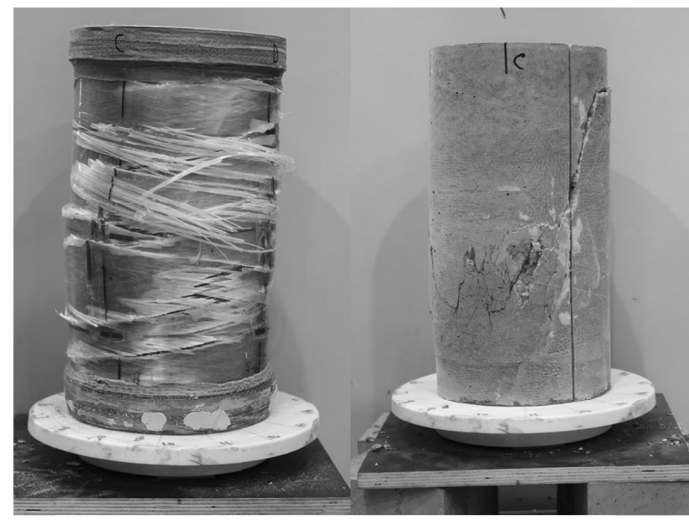

S54-2FW-C2

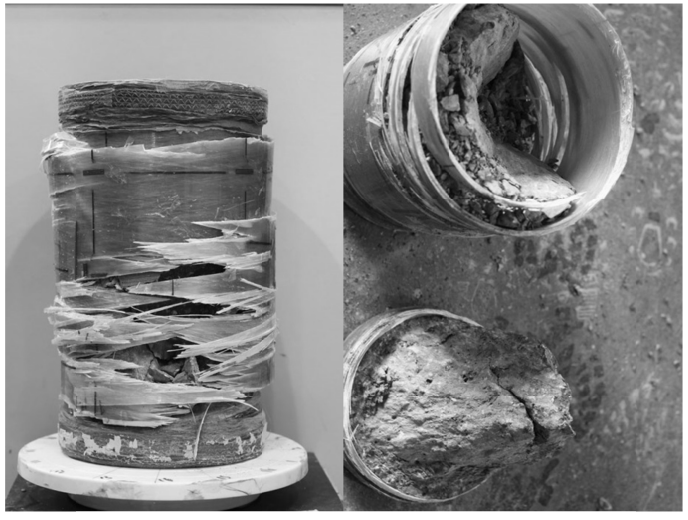

S84-4FW-C

Figure 6: Typical failed specimens 


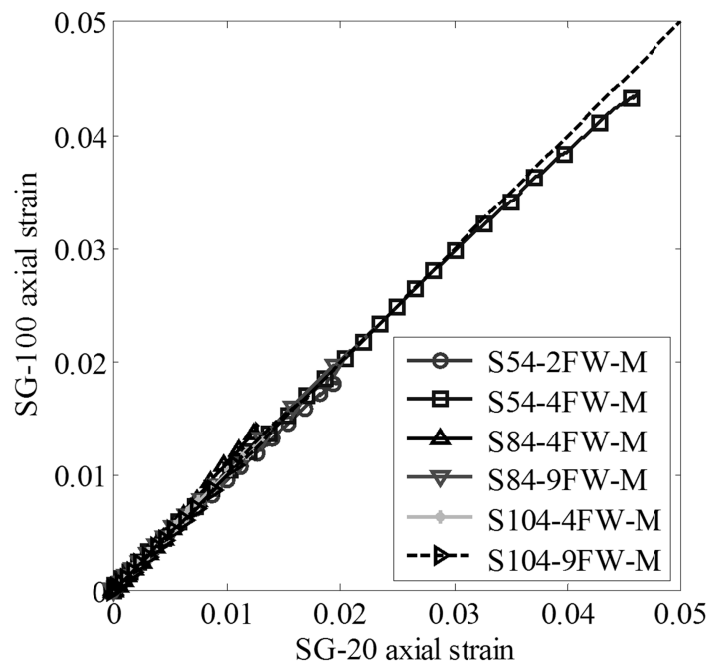

(a) SG-100 axial strains versus SG-20 axial strains

Figure 7: Comparison of axial strains obtained using three different methods 


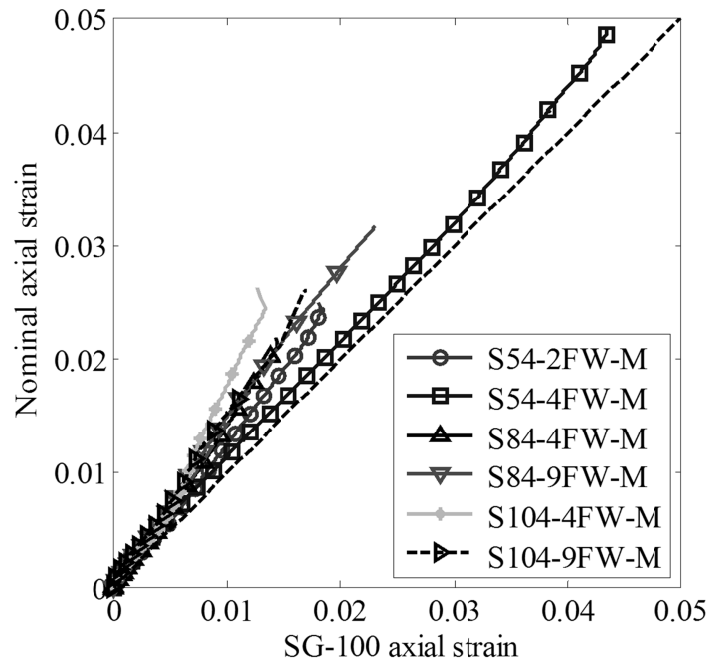

(b) Nominal axial strains versus SG-100 axial strains

Figure 7: Comparison of axial strains obtained using three different methods (continued) 


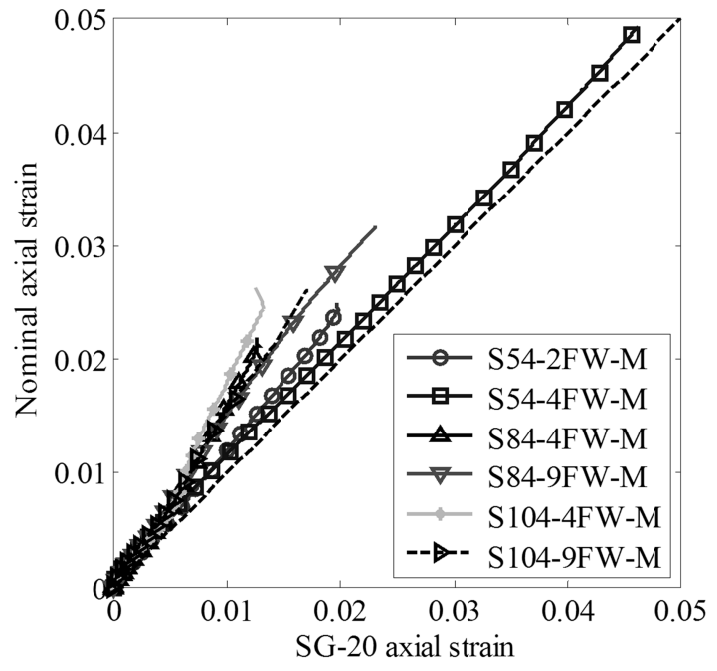

(c) Nominal axial strains versus SG-20 axial strains

Figure 7: Comparison of axial strains obtained using three different methods (continued) 


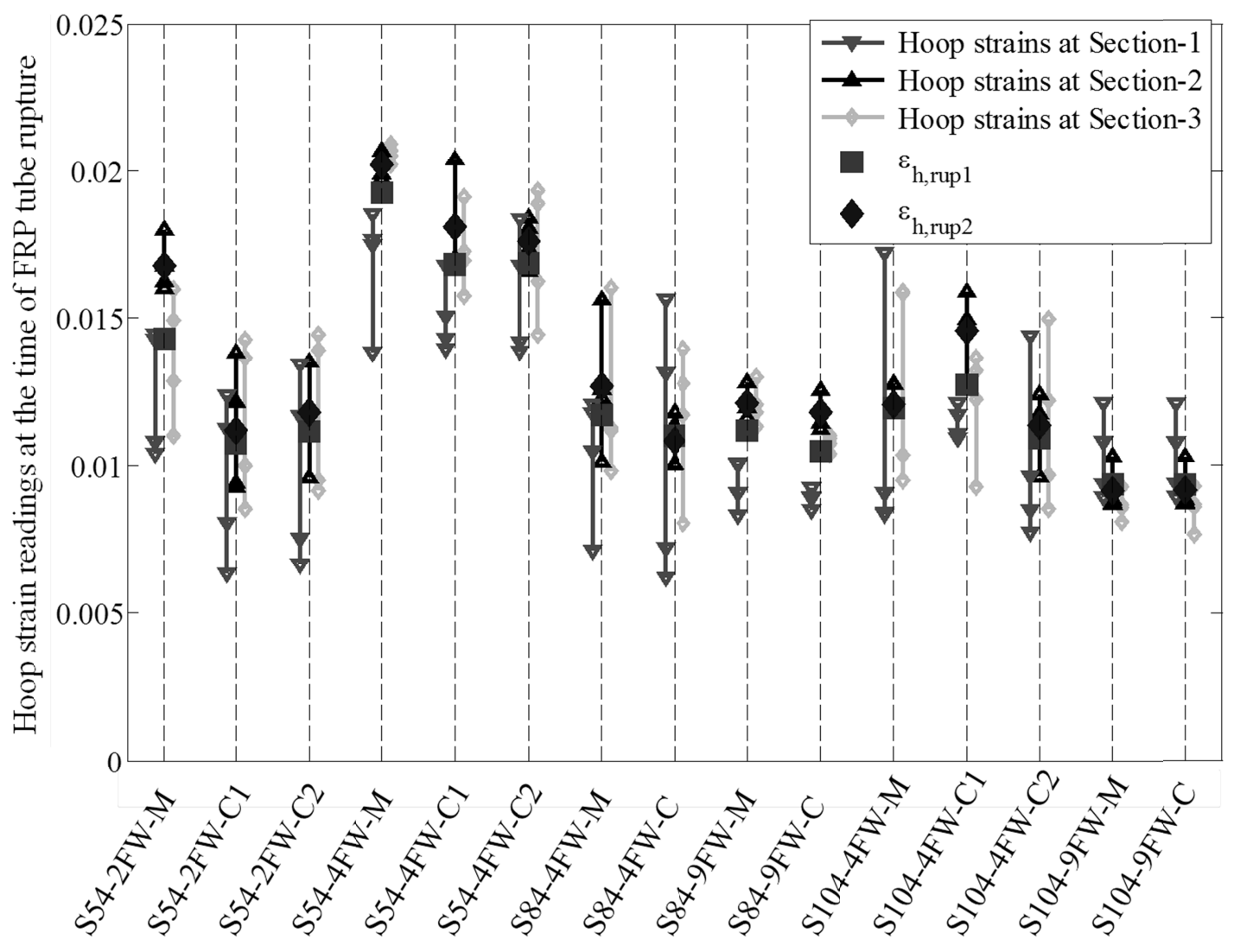

Figure 8: Hoop strain distributions 

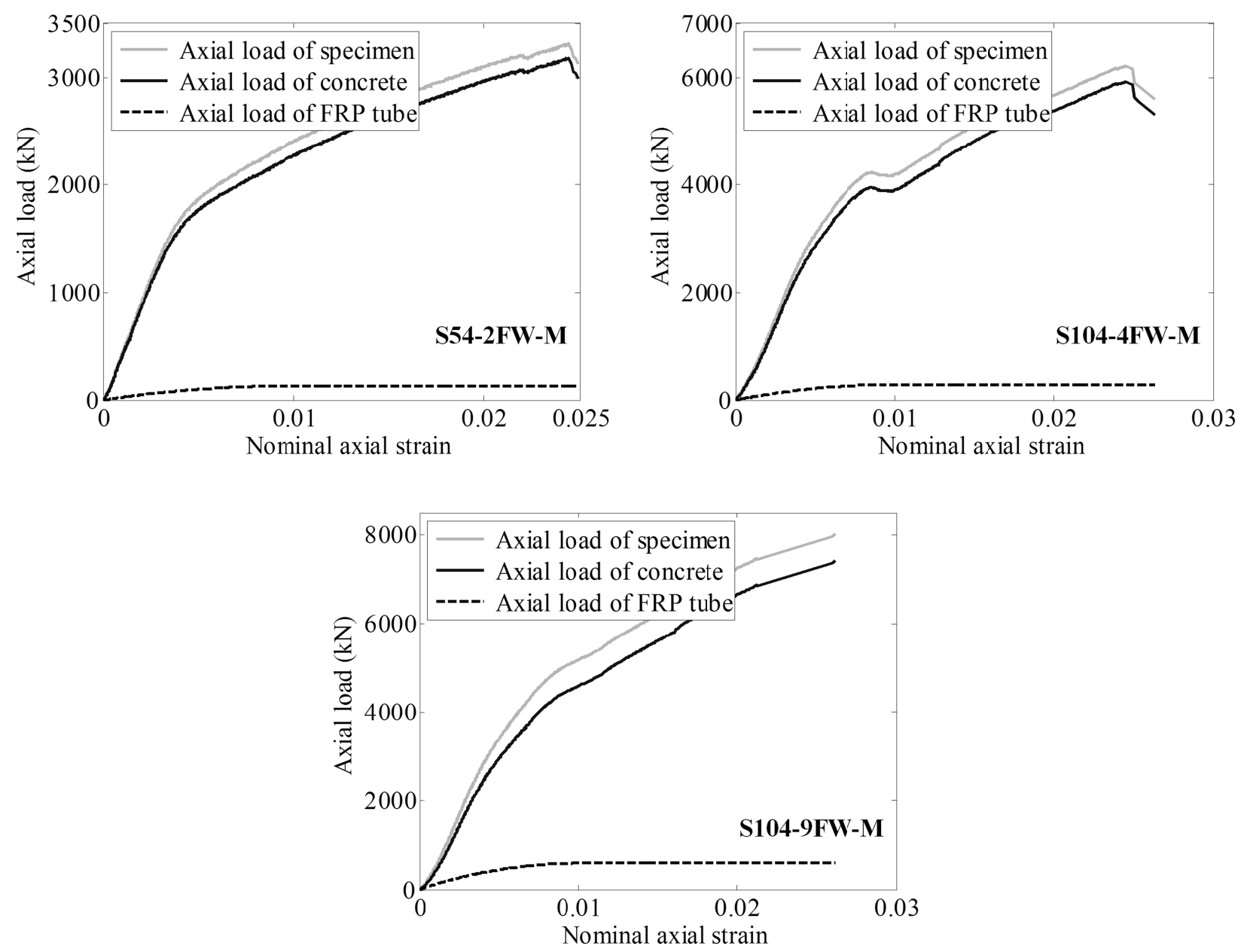

(a) CFFTs subjected to monotonic axial compression

Figure 9: Typical axial load-axial strain curves 

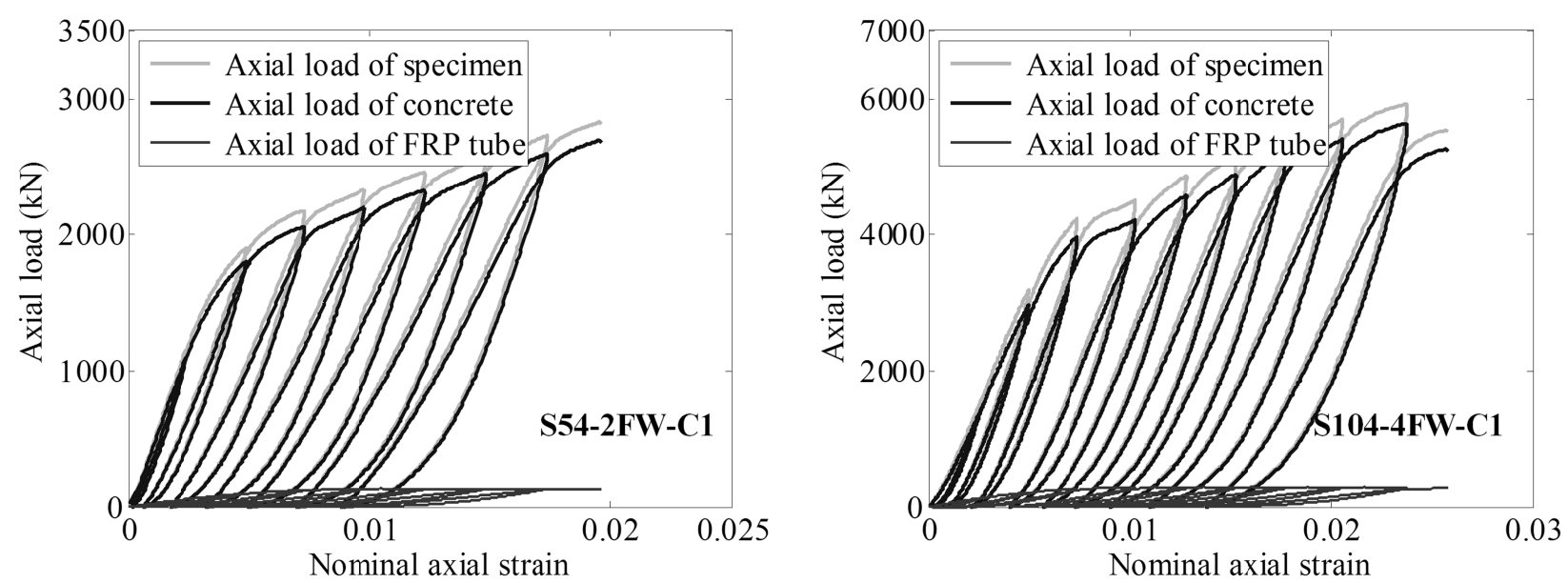

(b) CFFTs subjected to cyclic axial compression

Figure 9: Typical axial load-axial strain curves (continued) 

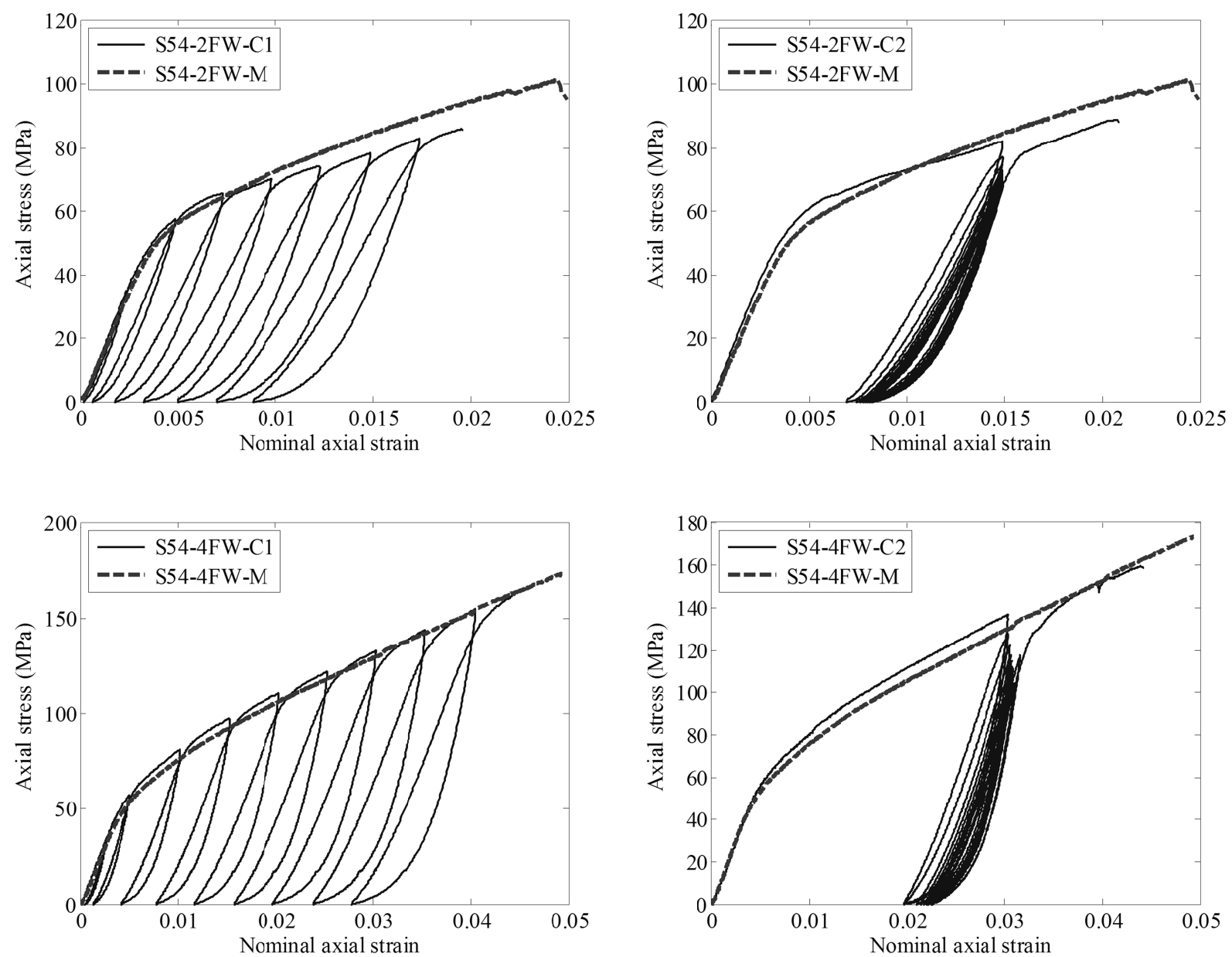

(a) Specimens of Batch-1

Figure 10: Axial stress-strain curves 

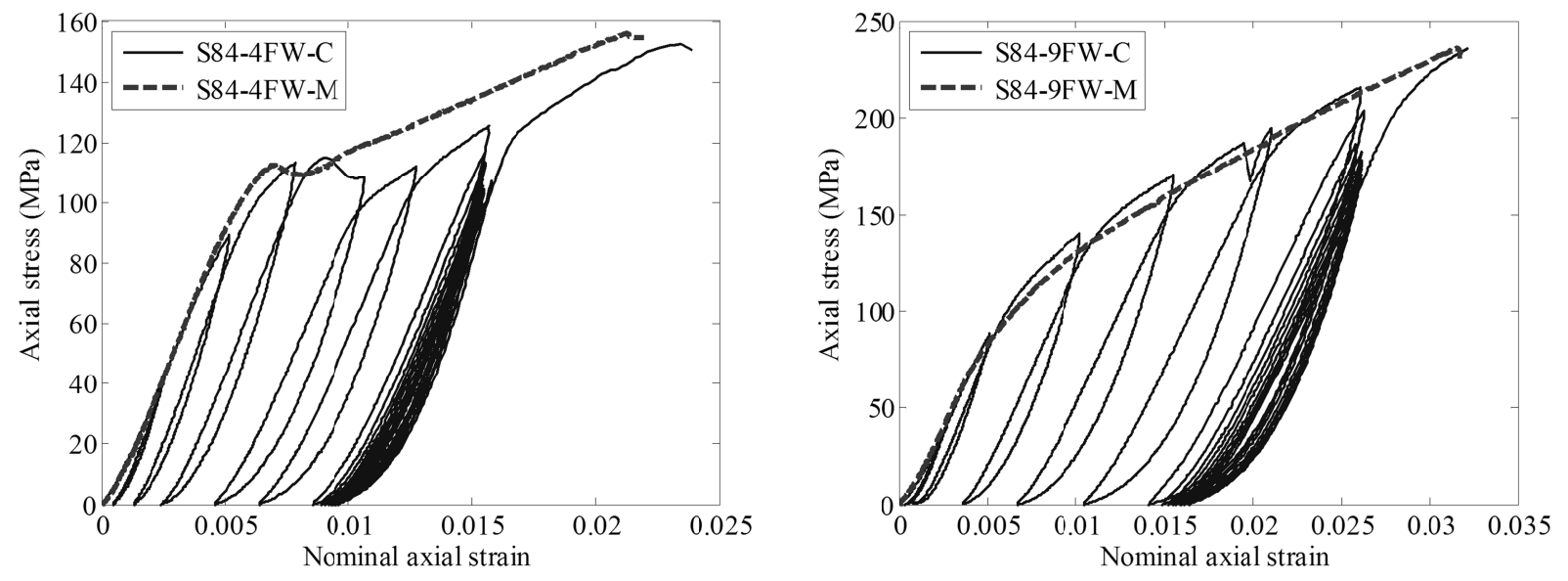

(b) Specimens of Batch-2

Figure 10: Axial stress-strain curves (continued) 

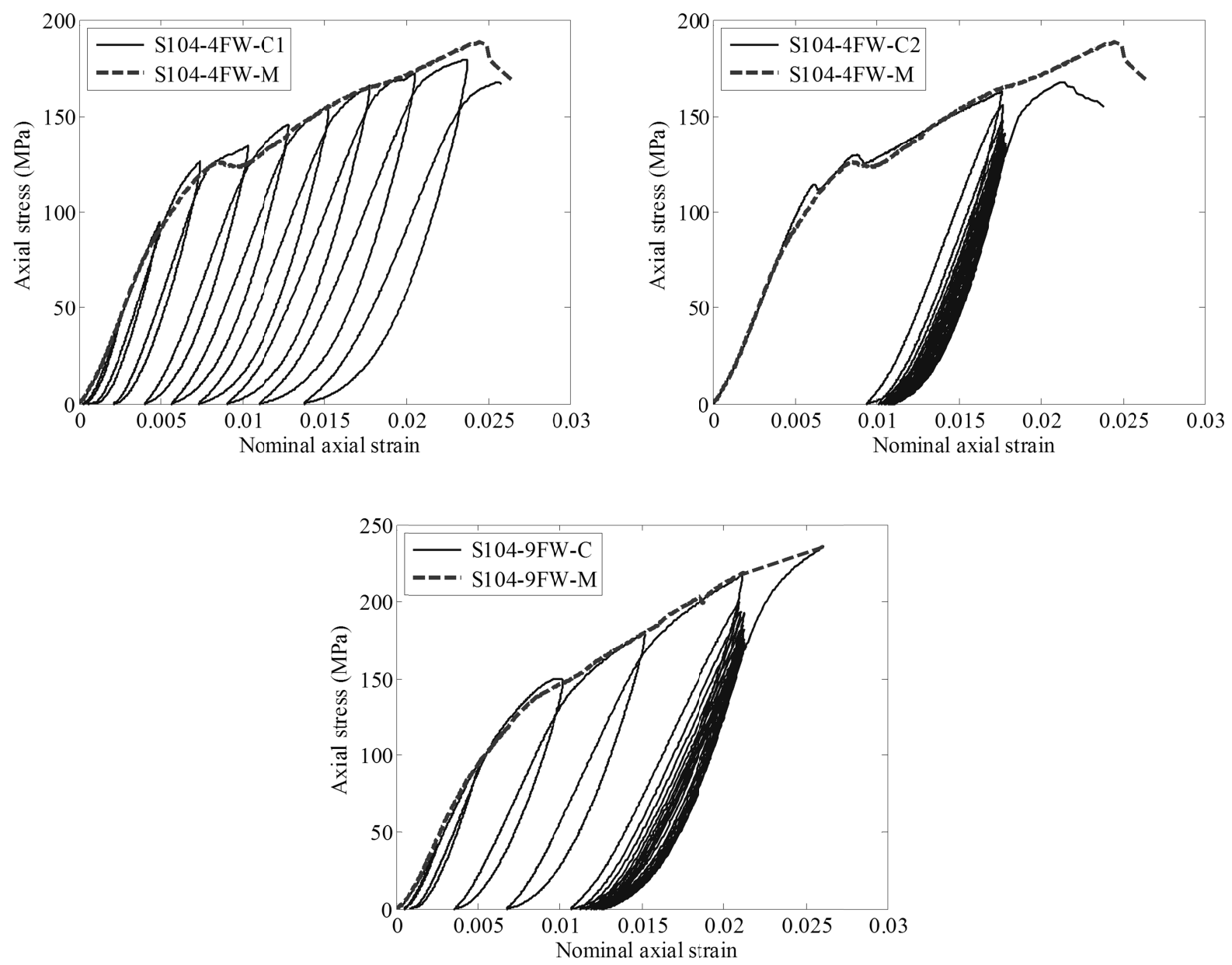

(c) Specimens of Batch-3

Figure 10: Axial stress-strain curves (continued) 


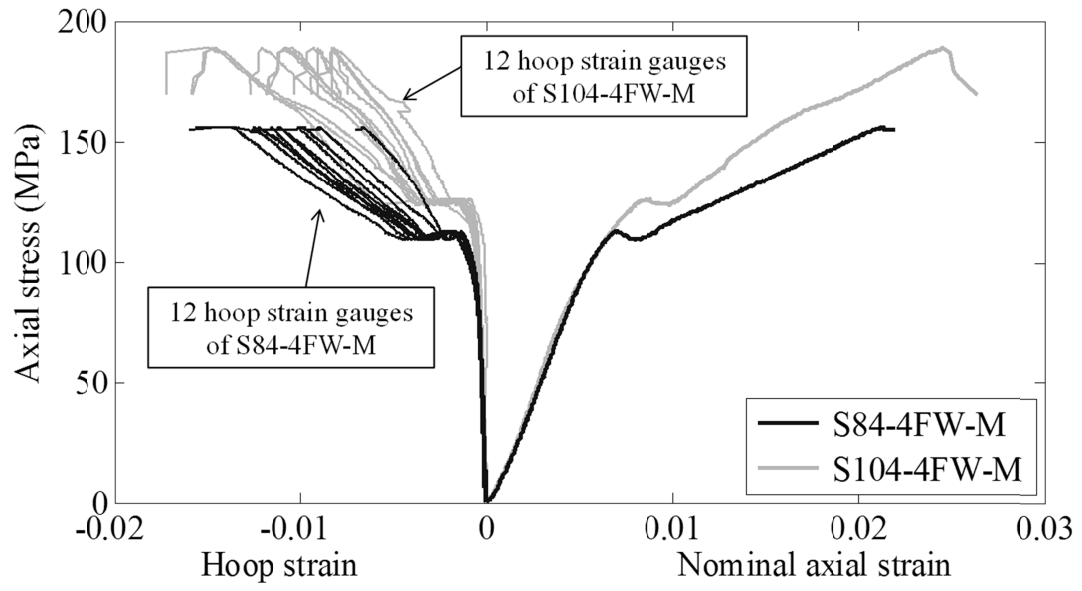

Figure 11: Sudden increase in hoop strain 

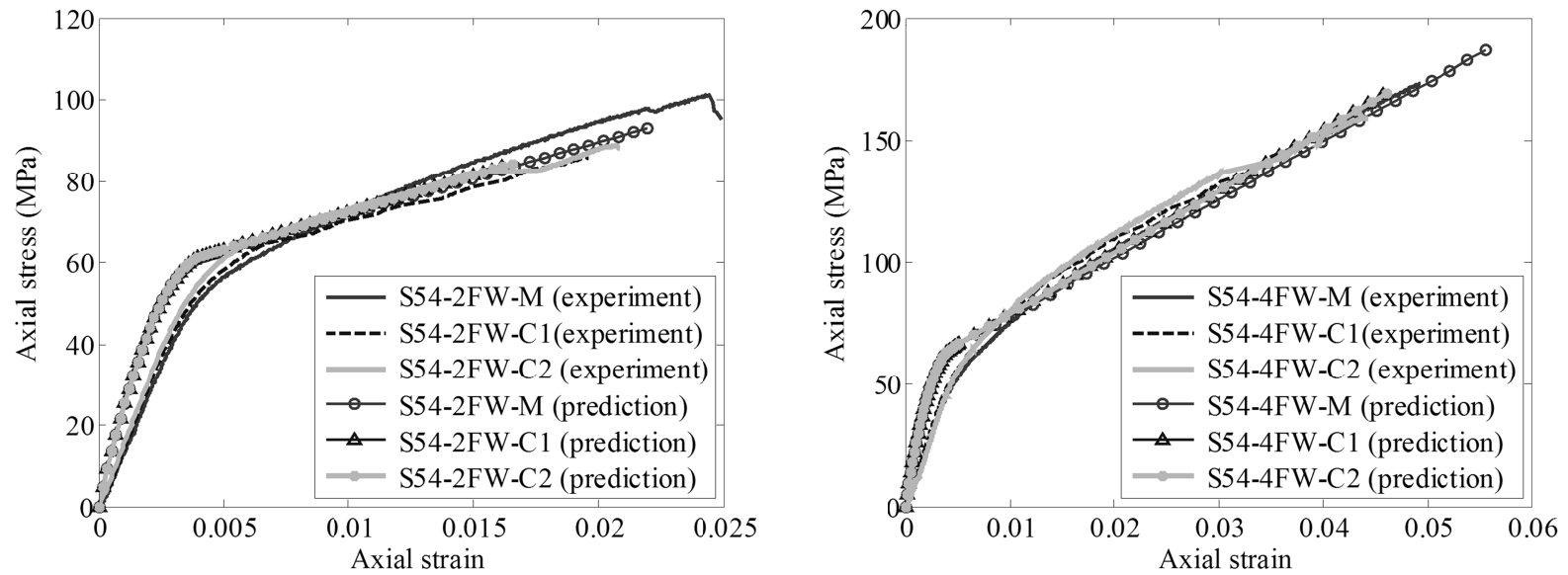

(a) Specimens of Batch-1

Figure 12: Envelope stress-strain curves 

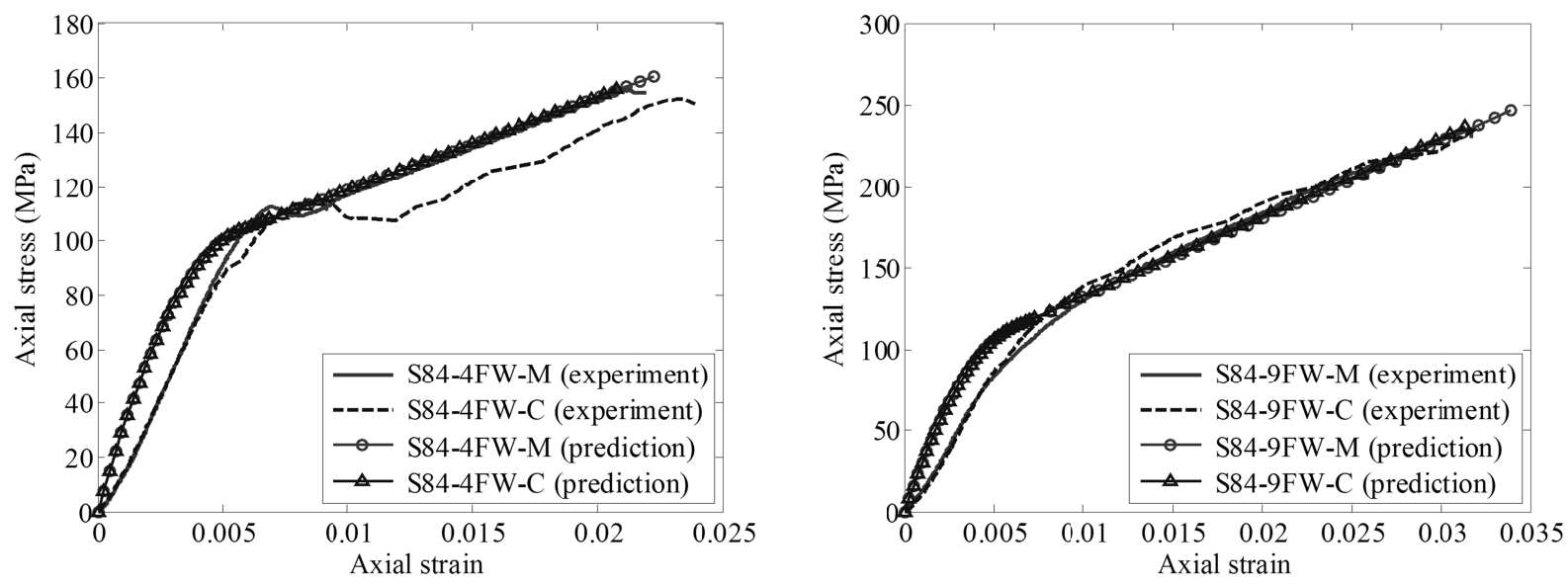

(b) Specimens of Batch-2

Figure 12: Envelope stress-strain curves (continued) 

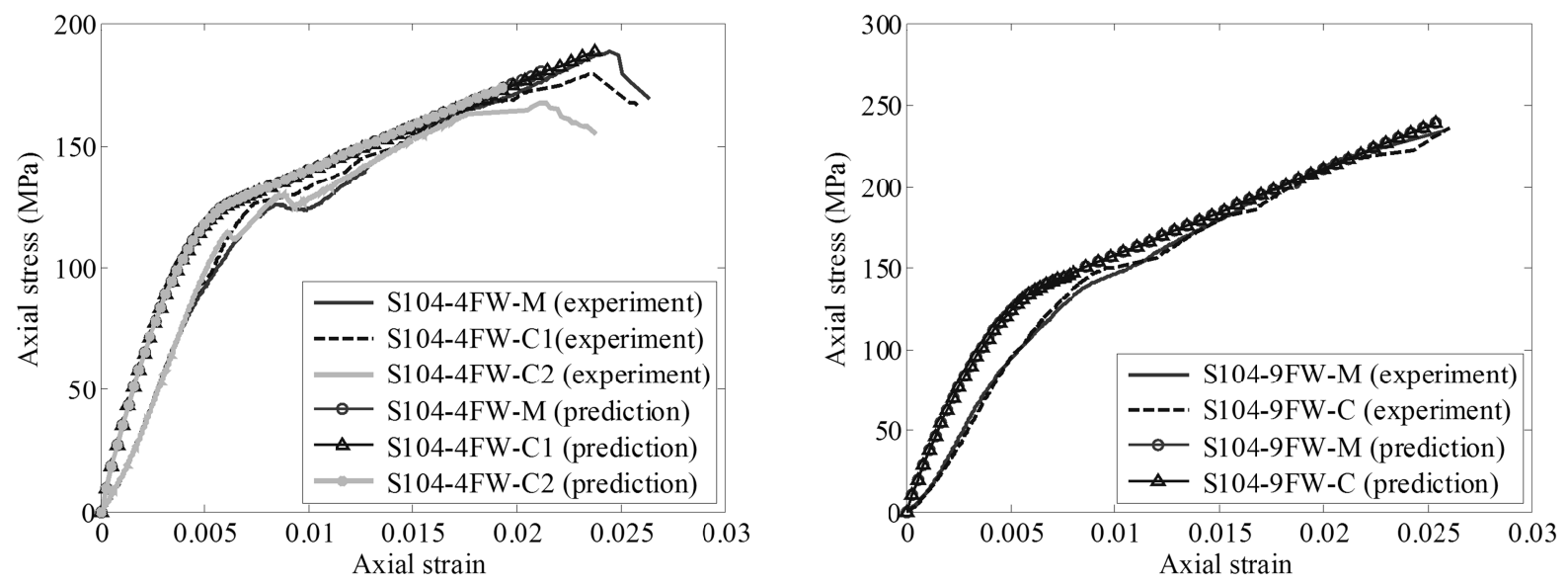

(c) Specimens of Batch-3

Figure 12: Envelope stress-strain curves (continued) 

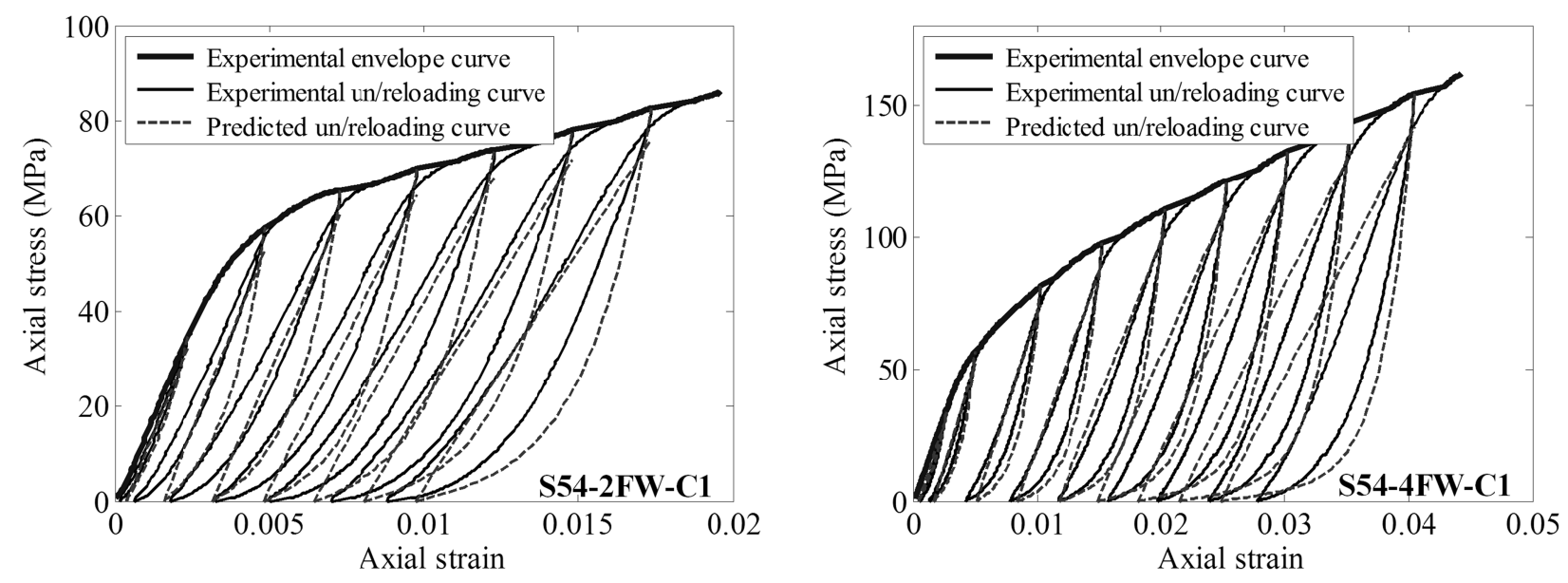

(a) Specimens of Batch-1

Figure 13: Performance of Lam and Teng's (2009) model for envelope unloading/reloading curves 

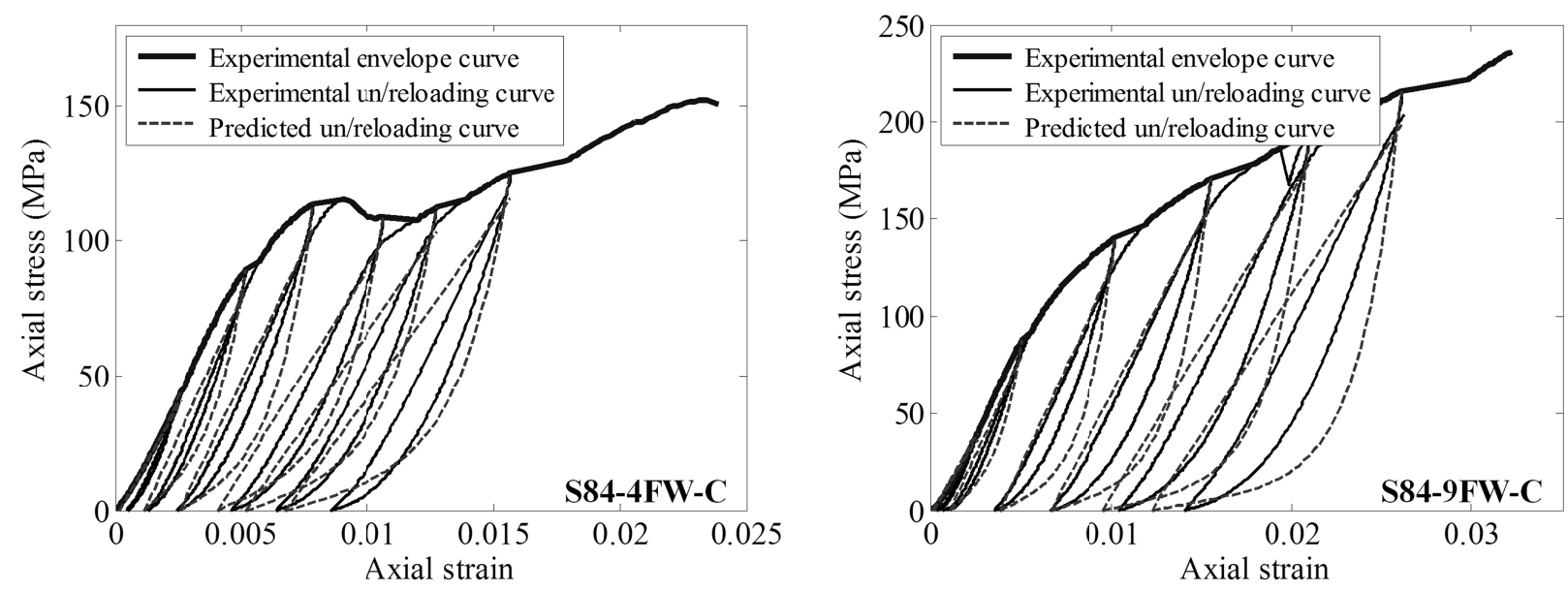

(b) Specimens of Batch-2

Figure 13: Performance of Lam and Teng's (2009) model for envelope unloading/reloading curves (continued) 

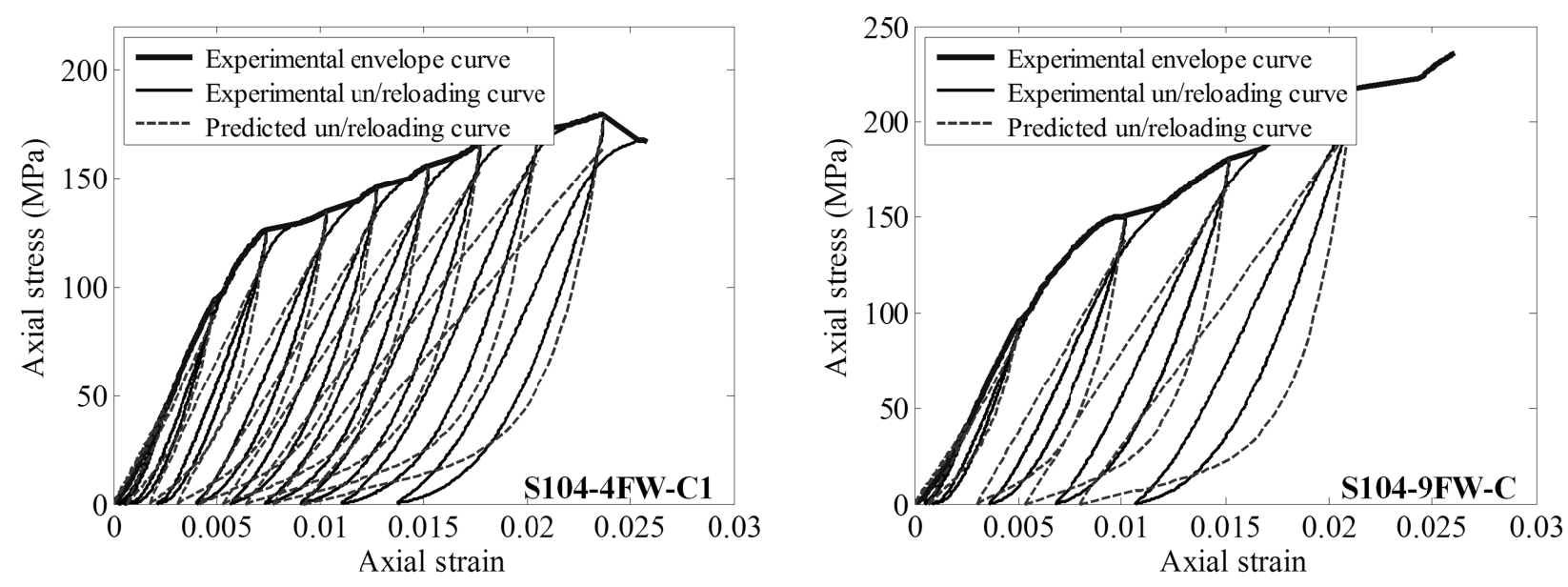

(c) Specimens of Batch-3

Figure 13: Performance of Lam and Teng's (2009) model for envelope unloading/reloading curves (continued) 

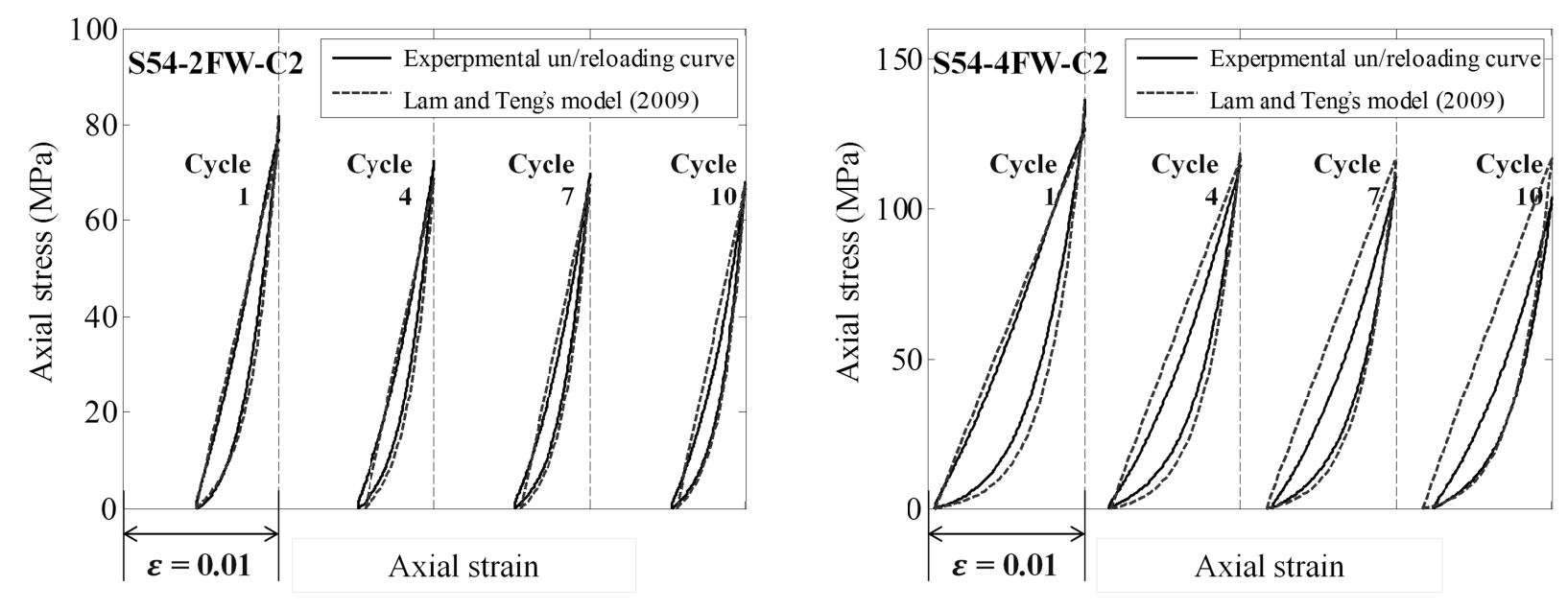

(a) Specimens of Batch-1

Figure 14: Performance of Lam and Teng's (2009) model for repeated unloading/reloading cycles 

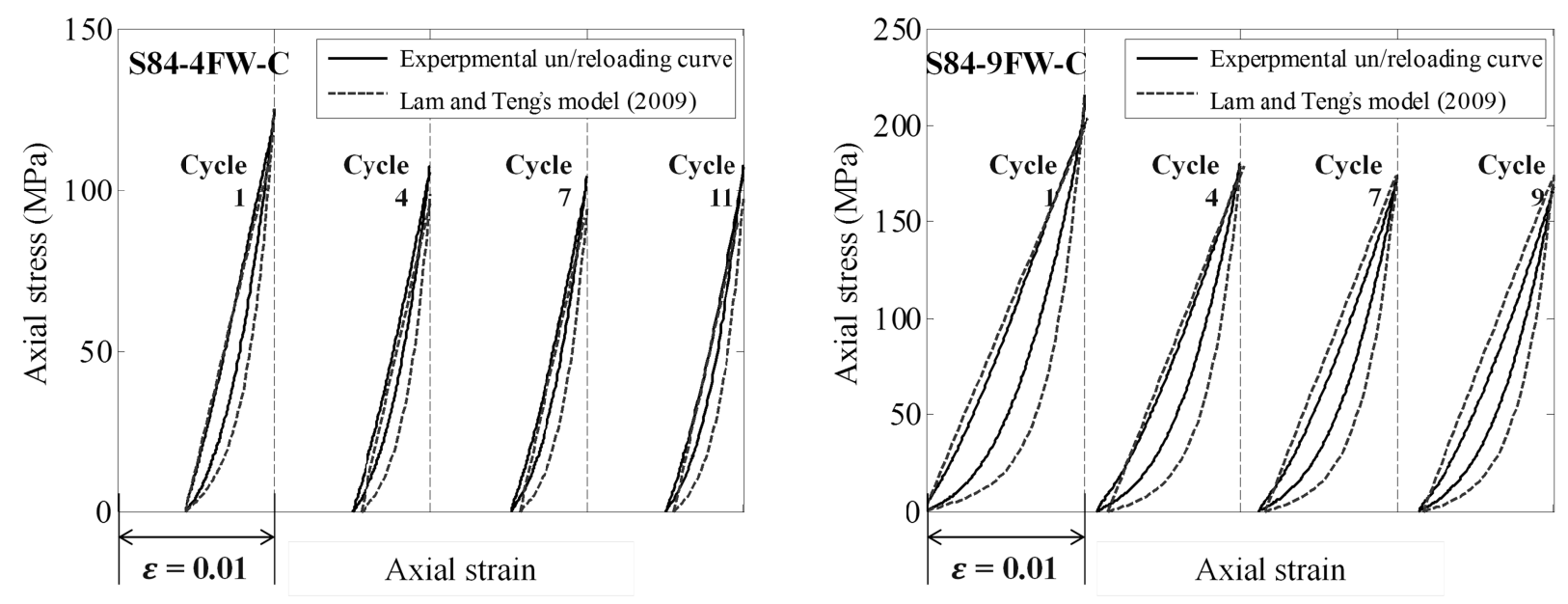

(b) Specimens of Batch-2

Figure 14: Performance of Lam and Teng's (2009) model for repeated unloading/reloading cycles (continued) 

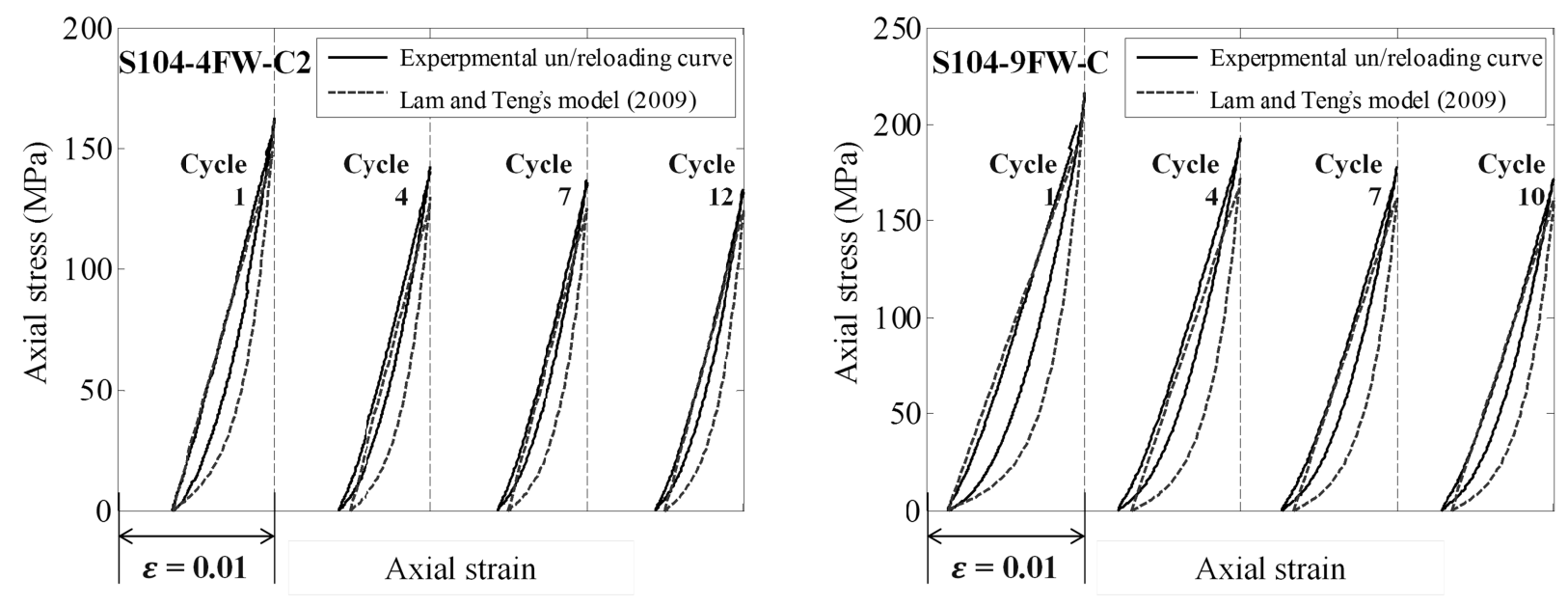

(c) Specimens of Batch-3

Figure 14: Performance of Lam and Teng's (2009) model for repeated unloading/reloading cycles (continued) 